\title{
PROPIEDADES ECLESIÁSTICAS EN UNA CIUDAD ADUANERA: LOS JESUITAS EN ORDUÑA, 1689-1767
}

\author{
POR \\ Rosario Porres MariJuÁn \\ Universidad del País Vasco / EHU
}

\section{RESUMEN}

El colegio de los jesuitas de Orduña, uno de los más tardíos de todo el País Vasco, sigue en su fundación un patrón característico en los casos de mecenazgo indiano: benefactor oriundo, capital consolidado sobre el comercio y el servicio de la Corona, y diseño dirigido desde el otro lado del Atlántico, en este caso desde el Perú. El presente artículo aporta algunas claves sobre esas cuestiones, y ahonda en la formación del patrimonio que la Compañía de Jesús logró reunir en esta ciudad aduanera del Señorío de Vizcaya hasta el momento de la expulsión decretada por el rey Carlos III.

Palabras Clave: Jesuitas, Compañía de Jesús, Orduña, Bilbao, clero, patrimonio

\section{ECCLESIASTIC REAL ESTATES IN A CUSTOMS-TOWN: THE JESUITS IN ORDUÑA, 1689-1767}

\begin{abstract}
The Jesuit school in Orduña, though one of the last foundations in the Basque Country, follows the classical pattern of indiano sponsorship: a local benefactor,
\end{abstract}

\footnotetext{
${ }^{*}$ El presente estudio se ha realizado en el marco del Proyecto de Investigación de I+D Entre el fervor y la violencia: la sociedad vasca y la Iglesia en la Edad Moderna [HAR2011-28427] financiado por el Ministerio de Ciencia e Innovación.

${ }^{* *}$ Abreviaturas. (AHN) Archivo Histórico Nacional; (AHBBVA) Archivo Histórico del Banco Bilbao Vizcaya Argentaria; (AFSSV) Archivo de la Fundación Sancho el Sabio de Vitoria.
} 
capital consolidated on trade and on services to the Crown, and a design supervised from overseas, in this particular case from Peru. This essay provides some keys to these issues and goes into greater detail in looking at the formation of the patrimony of the Society of Jesus in this town in Biscay until they were expelled by order of King Charles III.

KEY WORDS: Jesuits, Society of Jesus, Orduña, Bilbao, clergy, patrimony.

Recibido/Received 2010-09-20

Aceptado/Accepted 2011-01-27

Corrían los tiempos del extrañamiento de los jesuitas cuando el ilustrado José Antonio Armona y Murga, nacido en Orduña y funcionario en activo al servicio de la Corona, ${ }^{1}$ juzgaba con ironía cómo en los siglos anteriores las órdenes religiosas, y en particular la Compañía de Jesús, apoyándose en lo que él denominaba devotos por costumbre habían ido fundando por todas partes con magnificencia, ostentación y lujo, sin importarles que las familias de sus magnánimos fundadores quedasen para pedir limosna. A fin de cuentas, decía tomando las palabras de un político bellaco y decidor del siglo XVII, para ganar el cielo, ya no se necesitaba más que dejar a los regulares cuanto tenía cada uno en el suelo y en la bolsa. Buen ejemplo de ello había sido su paisano Juan de Urdanegui López de Inoso, el rico indiano fundador del colegio de Jesús, José y María de los jesuitas de Orduña, pues después de que muriera en manos de sus piadosos directores...sus nietos andan por España sin tener hoy que comer. ${ }^{2}$ Duras y sorprendentes palabras sin duda, más aún en boca de quien apenas unos años después, en 1783, ejercería como prefecto de la Real Congregación de los vascos de Madrid dedicada precisamente a la advocación de San Ignacio de Loyola. ${ }^{3}$

Cabe decir sin embargo que por lo que respecta al País Vasco los jesuitas nunca lo tuvieron fácil, a pesar del origen guipuzcoano del fundador de la Orden y del empuje que sus parientes los Idiáquez dieron repetidamente a su obra. Y menos cuando trataron de asentarse en los núcleos urbanos. En Bilbao necesitaron más de sesenta años de intrigas hasta fundar a partir de 1604, en San Sebastián una historia turbulenta -como en su día la calificó Tellechea Idígoras- ${ }^{4}$ de

\footnotetext{
${ }^{1}$ Entre otros cargos fue miembro del Consejo de S. M., Intendente del Ejército y Provincia y Corregidor de Madrid. Álvarez Barrientos, J. 1989 José Antonio de Armona y Murga, corregidor de Madrid en tiempos de Carlos III. Madrid: Artes Gráficas Municipales.

${ }^{2}$ Salazar Arechalde, J. I. (ed.) 2002. Apuntaciones históricas y geográficas de la antigüedad, nombre y privilegios de la ciudad de Orduña en el M. N. y M. L. Señorio de Vizcaya: 123. Bilbao: Diputación Foral de Vizcaya. Instituto de Estudios Territoriales de Bizkaia.

${ }^{3}$ Angulo Morales, A. 1999. «La Real Congregación de San Ignacio de Loyola de los naturales y originarios de las tres Provincias Vascas en la Corte de Madrid (1713-1896)», en A. Garritz (coord.), Los vascos en las regiones de México: 15-34. México: Universidad Nacional Autónoma de México.

${ }^{4}$ Tellechea Idígoras, J. I. 1997. Una historia turbulenta. La fundación de la Compañía de Jesús en San Sebastián (1619-1627). San Sebastián: Fundación Social Cultural Kutxa; Sobre Bilbao, Porres Marijuán, R. 2005 «La Compañía de Jesús en las ciudades vascas: intrigas políticas y agitación social en la fundación de los colegios de Vitoria y Bilbao (1577-1604)» en E. García Fernández (ed.), Bilbao,
} 
nueve hasta lograrlo en 1627, y en Vitoria nada menos que dos siglos completos para ver colmados sus objetivos en 1751, con apenas tiempo ya de instalarse antes de que Carlos III decretase la expulsión. ${ }^{5}$ En Orduña también les costó lo suyo, a juzgar por los diecisiete años de vacilaciones que precedieron a la fundación en esa localidad.

\section{ORDUÑA CIUDAD MERCANTIL Y ADUANERA}

Era Orduña uno de esos núcleos que siempre resultaron atractivos para los ignacianos. Porque aunque es cierto que se interesaron primeramente por los centros universitarios, ${ }^{6}$ nunca perdieron de vista aquellas otras ciudades que, a la par de populosas, gozaban de un fuerte desarrollo económico. Si éste procedía del comercio tanto mejor, porque el tráfico mercantil posibilitaba la multiplicación de conventos de todas las órdenes, pues solía traducirse en riqueza y ésta en legados, limosnas y dotación de memorias piadosas. ${ }^{7} \mathrm{Y}$ esto era tanto más importante para los jesuitas, que desde sus comienzos, y a pesar de lo que marcaban sus estatutos, se sumieron de lleno en los negocios seculares, utilizando las redes mercantiles para financiarse, transferir dinero hacia ámbitos diversos, y para hacerse con una abundante y siempre conveniente información. ${ }^{8}$

De hecho, aunque su actividad económica más habitual fuera la explotación de sus propiedades rústicas -baste, por ejemplo, el recuento de los bienes del cercano colegio de Villagarcía de Campos especializado en ganadería ovina- ${ }^{9}$ nunca despreciaron el crédito, ni el comercio, incluso el transoceánico, apro-

Vitoria y San Sebastián, espacios para mercaderes, clérigos y gobernantes: 185-250. Bilbao: Servicio Editorial de la Universidad del País Vasco/EHU; Porres Marijuán, R. 2009». Las redes mercantiles atlánticas y la instalación de los jesuitas en Bilbao, 1551-1604» en I. Dubert y H. Sobrado (eds.), El mar en los siglos moderno: 499-511. Santiago de Compostela: Universidad Santiago de Compostela.

${ }^{5}$ Benito Aguado, T. 2001. «La resistencia al asentamiento de los jesuitas en el País Vasco: Vitoria (1583-1751)» en R. Porres Marijuán (ed.), Poder, resistencia y conflicto en las Provincias Vascas, siglos XV-XVIII: 339-366. Bilbao: Servicio Editorial de la Universidad del País Vasco/EHU; Benito Aguado, T. 2001. La sociedad vitoriana en el siglo XVIII: el clero, espectador y protagonista. Bilbao: Servicio Editorial de la Universidad del País Vasco/EHU; Porres Marijuán, R. 1989. Gobierno y administración de la ciudad de Vitoria en la primera mitad del siglo XVIII. Vitoria: Diputación Foral de Álava; Porres Marijuán R. y Benito Aguado, T. 2000. «El estatuto de limpieza de sangre y sus repercusiones en Vitoria en tiempos de Felipe II». Hispania, LX/2, 205: 515-562.

${ }^{6}$ Egido, T. (coord.). 2004. Los jesuitas en España y en el mundo hispánico: 50-51. Madrid: Marcial Pons. Ediciones de Historia.

${ }^{7}$ López Martínez, A. 1992. La economía de las órdenes religiosas en el Antiguo Régimen. Sus propiedades y rentas en el reino de Sevilla: 37. Sevilla: Diputación Provincial.

${ }^{8}$ Galán García, A. 1995. El Oficio de Indias de los jesuitas en Sevilla, 1566-1767: 96-103. Sevilla: Fundación Fondo de Cultura.

${ }^{9}$ El colegio de Villagarcía poseía y administraba al menos cuatro granjas o fincas agropecuarias de gran envergadura. Tan sólo en la de la propia localidad, el Catastro de Ensenada de1752 señalaba, entre otros ganados, 2.400 cabezas de ovino. Rivera Vázquez, E. 1991. «Crónica General de la Provincia de 
vechando que la Corona eximió de impuestos las mercancías que enviaban a América para el uso de sus colegios, siempre y cuando se excusaran de venderlas. Pero sabido es que este requisito no siempre se cumplía, ${ }^{10}$ como lo es que en España los casos de jesuitas dedicados a menesteres seculares no fueron ni mucho menos puntuales. Hasta los propios generales de la Compañía cayeron habitualmente en esa tentación, contraviniendo las prohibiciones de la Orden y, en más de una ocasión, sus propias disposiciones. ${ }^{11}$

Cuando en el último tramo del siglo XVII se acercaron a Orduña, esta pequeña ciudad amurallada que debía rondar los 1.000 habitantes o poco más, era un activo núcleo mercantil. Desde hacía siglos se celebraban entre sus muros dinámicos mercados semanales y ferias anuales tan conocidas como las que tenían lugar en Guernica y Bilbao. En ellas daban salida a sus productos y a sus servicios los artesanos vizcaínos y guipuzcoanos (ferrones, armeros, cordeleros, ancoreros), los transportistas de vena, hierro y cereales, los pescadores, los mareantes, etc., que las aprovechaban a su vez para adquirir bienes de consumo, en lo fundamental tejidos y alimentos. ${ }^{12}$ Pero si algo singularizaba a esta localidad vizcaína eran sus aduanas, las más importantes, junto con las de Valmaseda y Vitoria, en el llamado Distrito Aduanero de Cantabria, y paso obligado en el trasiego de mercaderías entre la meseta castellana y el puerto de Bilbao, a esas alturas el más importante del Cantábrico y, cuando menos desde el siglo anterior, un activo centro financiero. ${ }^{13}$

Es cierto que su momento de mayor esplendor habría de llegar después de la expulsión de la Compañía de Jesús, a raíz de la construcción del nuevo camino de acceso desde la meseta por la Peña de Orduña en 1772. Fue entonces cuando la ciudad cobró tal impulso económico que en apenas veinte años logró duplicar su población. En cambio en el siglo anterior las cosas no siempre habían ido bien. La preeminencia que sus aduanas y las de Valmaseda habían vivido respecto a las de Vitoria en el siglo XVI cambió a partir de 1604, cuando las

Castilla», en San Ignacio de Loyola y la Provincia jesuítica de Castilla: 288-289. León: Provincia de Castilla S. J.

${ }^{10}$ López Martinez, A. 2000. «Los jesuitas y su intermediación financiera en la Carrera de Indias» en A. M. Bernal (ed.), Dinero, moneda y crédito en la Monarquía Hispánica: 754. Madrid: Marcial Pons.

${ }^{11}$ Lozano Navarro, J. 2005. La Compañía de Jesús y el poder en la España de los Austrias: 58. Madrid: Cátedra.

${ }^{12}$ Fernández de Pinedo, E. 1998. «Los altibajos mercantiles del Consulado de Bilbao en los años 80 y 90» en L. A. Ribot y E. Belenguer (coords.), Las sociedades ibéricas y el mar a finales del siglo XVI. Tomo IV. La Corona de Castilla: 120-122. Madrid: Sociedad Estatal Lisboa'98.

${ }^{13}$ Priotti, J. P. 1999. «Una conquista al revés o la penetración de los mercaderes noreuropeos y americanos en la Península Ibérica», en O. Mazín Gómez (Eed.), México en el mundo hispánico. Vol. I: 214. Zamora: El Colegio de Michoacan. Colección Memorias; Priotti, J. P. 2003. «Protagonistas de la ciudad y comerciantes europeos en el mercado bilbaíno del siglo XVI». Bidebarrieta, XII: 339; Priotti, J. P. 2005. Bilbao y sus mercaderes en el siglo XVI. Génesis de un crecimiento: 178 y ss. Bilbao: Diputación Foral de Vizcaya. 
aduanas alavesas tomaron abiertamente la delantera -ingresando más del 60\% de los diezmos-, en un momento en el que no sólo las exportaciones de lana sino también una parte relevante del comercio total de importación y exportación se desviaron hacia los puertos de Guipúzcoa. Sin embargo la hora guipuzcoana llegaría a su fin antes de $1650^{14}$ y los trámites de la fundación del colegio de Orduña vendrían a coincidir precisamente con una etapa (1681-1685) en la que los bilbaínos habían recuperado ya una gran parte del tráfico comercial del Cantábrico, tras controlar de nuevo las exportaciones laneras desplazando a los puertos guipuzcoanos. ${ }^{15}$ Era un momento de plena expansión del sector de las exportaciones españolas de lana, como consecuencia de la demanda inducida desde los nuevos mercados de Holanda e Inglaterra y de los cambios acaecidos en las rutas y transporte de los mares europeos. ${ }^{16}$ En ese contexto expansivo llegaría para la Compañía de Jesús la oportunidad de establecerse en Orduña gracias al legado de un Urdanegui.

\section{EL FUNDADOR DEL COLEGIO DE ORDUÑA: CURSUS HONORUM DE DON JUAN DE URDANEGUI}

El fundador del colegio de Orduña había nacido en esta localidad en enero de 1619, en el seno de una familia originaria de la casería de Urdanegui en el Valle de Gordejuela, en las Encartaciones. Era tierra dependiente del Arzobispado de Burgos -a diferencia de gran parte de Vizcaya que pertenecía a la diócesis de Calahorra-, algo muy común entre cuantos se esforzaron siempre por favorecer la entrada de la Compañía en el Señorío. El abuelo paterno, Diego de Urdanegui, había nacido también en Orduña, aunque no había heredado la casa al ser apartado de acuerdo con el Fuero de Vizcaya. Al enviudar, la abuela María de Menoyo se instaló con su hijo el primer Juan de Urdanegui en el pueblo de su familia,

\footnotetext{
${ }^{14}$ La captación por parte de Bilbao del flujo de las lanas, aunque anterior, se consolidó después de 1648. Observando las medias anuales de exportación de lanas por el Cantábrico se aprecia que mientras en el periodo 1621-1626 la media anual de exportación de lanas fue de 12.350 arrobas de Bilbao y 42.200 por San Sebastián, en el periodo 1654-1655 se transformaron en 92.700 arrobas las que salieron por Bilbao y apenas 32.000 por San Sebastián, mientras que Deva pasó de 9.500 a cero. En otras palabras, ninguna saca por Deva, San Sebastián cediendo un $25 \%$ y Bilbao dando ya el gran salto hacia adelante en su comercio lanero. Bilbao, L. M. 2003. «Comercio y transporte internacionales en los puertos de Vizcaya y Guipúzcoa durante el siglo XVII (1600-1650. Una visión panorámica». Itsas Memoria. Revista de Estudios marítimos del País Vasco 4: 268-270.

${ }^{15}$ Bilbao, L. M. 1983. «Exportación y comercialización de lanas de Castilla durante el siglo XVII», en El pasado histórico de Castilla y León. Vol. II. Edad Moderna: 225-243. Burgos: Junta de Castilla y León. Consejería de Educación y Cultura.

${ }^{16}$ Esta bonanza aún se dejaba sentir en los primeros años del siglo XVIII, cuando las aduanas de Orduña y Balmaceda todavía seguían llevando ventaja sobre las vitorianas. Bilbao, L. M. 1994. «La economía de la Provincia de Álava en la etapa foral, 1458-1876» en Actas de las Juntas Generales de Álava. Vol. 5: LXXXVII. Vitoria: Juntas Generales de Álava.
} 
Retes de Tudela, en el valle alavés de Ayala. Fue él quien, siendo ya mozo, retornó a Orduña junto a un tío materno rico y principal, Sebastián de Trasviña, en cuya casa vivió en régimen de pupilaje ejerciendo como aprendiz de zapatero. Durante esa estancia fue casado en 1613 con Francisca López de Inoso, sobrina de la esposa de Trasviña, a quien servía como criada. Con el propio esfuerzo y la ayuda de algunos familiares de los Inoso -entre otros una cuñada soltera y con posibles que fue doncella de la condesa de Ayala- y un deudo que tuvieron en Indias, los recién casados fueron comprando hacienda: una casa en la calle Burgos de Orduña, y algunas heredades y viñas que les rentaban al año entre 60 y 70 fanegas de trigo, 30 de cebada y 400 cántaras de vino. ${ }^{17}$ Una hacienda que años después pasará a la Compañía de Jesús como parte del legado del fundador.

Pronto daría el zapatero Urdanegui muestras de albergar más altas aspiraciones sociales. Una de ellas, su entrada en la cofradía de hidalgos de Santo Domingo y San Iñigo de la parroquia de San Juan de la localidad alavesa de Aloria -pegante a Orduña-, en la que llegó a ejercer incluso como mayordomo en 1625. La condición de cofrade se transmitía de padres a hijos o de suegros a yernos, siempre casados y residentes en Orduña o en el aledaño valle alavés de Arrastaria. Y éste fue el caso de Juan, al que su condición de cofrade le vino dada por yerno, por serlo de Martín de Inoso, y cabe suponer que después de cursar la correspondiente solicitud «el primer dia de Santo Domingo que biniere en el año después que fuere casado», y tras la pertinente información de limpieza de sangre que marcaban los estatutos. ${ }^{18}$ Pero además, para cuando este Urdanegui falleció en 1632, había logrado culminar su ascenso social ejerciendo como regidor de Orduña, y en su testamento, otorgado el 29 de marzo de ese mismo año, ordenó ser enterrado con el hábito franciscano en una sepultura propia adquirida en el convento de San Francisco.

Siete años después de la muerte de su padre, hacia 1639, y con apenas veinte años, nuestro protagonista Juan de Urdanegui embarcó en Portugalete rumbo a Silex.

${ }^{17}$ Otazu, A. y Díaz de Durana, J. R. 2008. El espíritu emprendedor de los vascos: 260. Madrid:

${ }^{18}$ Esta circunstancia no está del todo clara. La cofradía, disponía de unas ordenanzas de 32 capítulos, aprobadas el 27 de mayo de 1610, confirmación y traslado de otras refrendadas en 2 de julio de 1527 que a su vez recogían costumbres muy viejas de la cofradía cuya antigüedad se remontaba a más de 300 años según se decía en 1667. Cuando en esas fechas los informantes del hábito de nuestro general se desplazaron a Aloria para interrogar al mayordomo de la cofradía, aunque las ordenanzas nada decían sobre la nobleza o limpieza de sangre, el mayordomo apuntó oportunamente que nunca había podido entrar como cofrade quien no fuese hijo legítimo de sus padres, cristiano viejo, limpio de toda mala raza y raíz infecta y que no fuera hidalgo notorio de sangre «de todos cuatro costados». Además, cuando sacó el libro de registros, los informantes observaron que, a pesar de que nada se decía de ello en las ordenanzas, una mano anónima lo había encabezado con el título de: Libro de los caballeros hijosdalgo, sin raza de moros, judios, ni villanos, ni penitenciados por el Santo Oficio de la Inquisición de la Cofradía del Señor Sancti Iñigo de San Juan de Aloria. Un encabezado que casi respondía punto por punto a una de las preguntas que en los expedientes de Santiago debían hacerse a todos los testigos.

Hispania Sacra, LXIV

129, enero-junio 2012, 309-343, ISSN: 0018-215-X, doi: 10.3989/hs.2012.011 
Perú, instalándose en la Ciudad de los Reyes al amparo de su paisano el almirante Martín de Salcedo, con la esperanza de encontrar a aquel pariente materno que residía en la capital limeña. Fue sin embargo en el conocido como Puerto de Lima, la ciudad de El Callao, donde arribaba la Armada del Mar del Sur y donde se concentraba el tráfico marítimo que conectaba Perú con las ferias de Portobelo en el istmo de Panamá y con Nueva España, en la que Juan acabó asentándose. Comenzó con un empleo modesto, como soldado del presidio. Pero en muy poco tiempo inició una meteórica carrera, amparada en la sólida amistad que logró trabar con Diego Ortiz de Santecilla, secretario del virrey don Pedro de Toledo y Leiva, marqués de Mancera, que gobernaría Perú entre 1639 y 1648. Con la protección de don Diego, y sin que se sepa en calidad de qué, Urdanegui comenzó a realizar viajes en la Armada con el tesoro de S. M. desde El Callao hacia Panamá, donde llegaría a ser nombrado capitán de una de las compañías de infantería españolas que actuaban en la zona. De soldado del presidio de El Callao, pasando por custodio de transportes de caudales a bordo de la Armada del Mar del Sur, nuestro protagonista había llegado a ser capitán en Panamá, hacia donde al menos desde 1666 realizaba los embarques en navíos de su propiedad.

Fue precisamente en esa época, coincidiendo con el gobierno del virrey don Diego de Benavides y de la Cueva, conde de Santisteban del Puerto y marqués de Solera (1661-1666) -quien por cierto se había formado con los jesuitas del Colegio Imperial de Madrid-, cuando Juan de Urdanegui comenzó su verdadero ascenso social. Desempeñó entonces el oficio de Administrador General de los Almojarifazgos desde El Callao, impulsado al cargo por el Consulado de Lima, cuyo control estaba en aquellos momentos en manos de los mercaderes vascos que se asociaban en torno a la poderosa Hermandad de Aránzazu, creada hacia 1612 y de reconocida «filiación» franciscana. En realidad, ese fue el círculo en el que durante muchos años se movió Juan, como lo había hecho su padre y como lo hacían gran parte de los mercaderes vascos, cuya asociación con los franciscanos parecía indisoluble a pesar de que la influencia de la Compañía de Jesús en territorio peruano fue a más durante la primera mitad del siglo XVII. El Callao era frecuentemente el puerto de arribada de jesuitas procedentes del territorio panameño, y en otras muchas ocasiones puerto de embarque de los ignacianos hacia Panamá o Méjico. De hecho, desde 1613 existía en la ciudad un colegio de jesuitas fundado por el guipuzcoano Martín García Jáuregui, un mercader de enorme fortuna obtenida seguramente mediante el contrabando y reconvertido a jesuita antes de morir. ${ }^{19}$

\footnotetext{
${ }^{19}$ A mediados del siglo XVII los jesuitas disponían ya de tres colegios situados en las principales ciudades del Virreinato de Perú: Lima, Cuzco y Arequipa, y su influencia en el Perú virreinal iba en aumento.
} 
Pues bien, como sus inmediatos predecesores al frente de las rentas de las aduanas en El Callao habían sido caballeros de la Orden de Santiago, Urdanegui se empeñó en buscar el preciso lustre que le enfilara directamente hacia la obtención del hábito. Para ello nada mejor que un oficio en el regimiento de su ciudad natal, pues sabido es que en muchas localidades del País Vasco ese tipo de oficios eran garantía de la nobleza y limpieza de sangre indispensables en todo medre social que se preciase, y conferían mayor status en el contexto de una sociedad «de iguales» como era aquella en la que se reconocía la hidalguía universal. ${ }^{20}$ Corrió por ello suerte de alcalde en Orduña en 1659, cuando residía en Lima, aunque sólo alcanzó a ser procurador general. Pero Juan no se olvidó tampoco del «bagaje social» que le había dejado su padre, que como hemos visto no sólo había sido regidor en el ayuntamiento orduñés, sino mayordomo de una cofradía de hidalgos, circunstancia que solía presentarse como hecho fehaciente de hidalguía en las pruebas de ingreso en las Órdenes Militares. Varios testigos dieron fe de que la cofradía de San Juan de Aloria la conformaban exclusivamente los hidalgos, "cuyo estatuto se a obserbado y observa con tanto rigor que no se ha visto en tiempo alguno se aya admitido a dicha Junta ni dispensado con persona alguna que no sea hidalgo de quatro costados y christiano viejo», aunque como ya se ha dicho resuenen algunas dudas al respecto.

Sea como fuere, lo cierto es que para cuando en septiembre de 1668, con casi cincuenta años, se desposó con la limeña Constanza de Oviedo, Luján y Recalde -hija del general Francisco de Oviedo Luján Sigoney, que fuera Gentilhombre de Felipe IV, gobernador de Cayllona y teniente general del virrey del Perú en la costa venezolana de Barlovento-, era poseedor del hábito de la Orden de Santiago. Hasta entonces Urdanegui, que ya era general y alguacil mayor de la Inquisición en Lima, había estado muy unido a los franciscanos. La tradición familiar y su vinculación a la hermandad limeña de Aránzazu así lo confirman. Pero también la capilla de San Antonio de Padua, que había mandado erigir en el convento de San Francisco de Orduña y que debió ayudarle lo suyo en la fabricación de su nueva personalidad de caballero. En ella, y bajo una lámpara de plata peruana, se hallaba la tumba de sus padres, razón por la cual hizo al cenobio repetidas donaciones de objetos de plata-como también a la ermita de Nuestra Señora de la Antigua extramuros de la ciudad- a condición de que las prestasen convenientemente a las demás iglesias. ${ }^{21}$

\footnotetext{
${ }^{20}$ En el expediente incoado a Urdanegui para alcanzar el hábito, un testigo de Orduña -Álvaro de Llano y Velasco- hizo hincapié en que eran los oficios de Ayuntamiento «los que distinguen en esta ciudad los hijosdalgo de lustre de los hijosdalgo ordinarios y hombres comunes y pecheros, porque no se dan sino a tales hijosdalgo de lustre casa solar, estimación y hacienda y no hay otra distinción en esta ciudad».

${ }^{21}$ AHN. Clero-Jesuitas. Leg. 184. Exp. 2, sin foliar. Lo donado fue un tabernáculo de plata, una custodia dorada, un palio de tela con sus varas de plata y guión con su cruz y vara de plata y dos ciriales con sus blandones, todo de plata, con el objeto de que los franciscanos los usasen en el día y octava
} 
Pero tras su boda con la sobrina del jesuita Recalde su vinculación a los franciscanos fue remitiendo, aunque no acabaría de romperse hasta poco antes de su muerte. Era Constanza sobrina de Bartolomé de Recalde, un jesuita llegado al Perú a comienzos del siglo XVII que con el tiempo alcanzó los más altos cargos que el gobierno de la Compañía tenía en esa tierra, ejerciendo como rector en los colegios de Arequipa, El Callao, y más tarde en el de San Pablo de Lima, hasta sustituir a otro vasco, el padre Zurbano, como Provincial del Perú en 1649. Hasta el momento de su muerte acaecida en 1658, tanto él como el padre Juan de Urquiza, también de origen vasco, contribuyeron de forma notable a acrecentar la influencia de la Compañía entre la floreciente comunidad vasca de Lima, más allá del puro ámbito de sus familias.

Así pues, y aunque los contactos de Urdanegui con la Compañía son evidentes cuando menos dos años antes de su matrimonio en 1668, es indudable que tal acontecimiento debió pesar los suyo a la hora de trocar su vínculo franciscano por el de los ignacianos. En sus últimos suspiros Urdanegui buscó el consuelo espiritual en la Compañía, que se vio colmado al profesar personalmente en ella apenas tres días antes de su fallecimiento. Antes de que éste se produjera aún obtuvo la alcaldía de Lima (1679), y después un último honor que al parecer resultó póstumo: el título de marqués de Villafuerte (1683). Culminó así el cursus honorum de aquel antiguo soldado del presidio de El Callao, que había cimentado su fortuna desde su cargo de administrador de los reales almojarifazgos haciendo embarques a Panamá sobre navíos propios, hasta alcanzar el preciado título nobiliario. ${ }^{22}$

\section{Entre Castilla y Perú: la compleja tramitación del legado}

A decir verdad, aparte de sus donaciones a los franciscanos y a la ermita de la Antigua, sus primeras ideas piadosas para con su ciudad natal pasaron por hacer de la iglesia de Santa María, fundada en el siglo XIII y sin duda el templo más importante de Orduña, una colegiata, insuflando rentas para aumentar el número de sus beneficios a favor de los hijos de sus paisanos, y establecer un aniversario y un patronato a favor de sí mismo y sus sucesores. Pero es probable que se le pusieran algunas trabas, circunstancia que según Armona aprovecharon los jesuitas para hacerse con su dinero y su piadosa vocación, de modo que desde Lima se discutió el proyecto para un colegio de su ropa en vez de una colegiata canónica; y aun se dirigieron la fábrica, las dimensiones y las economías. No estuvo falto de razón el ilustrado, al menos en esta última parte

del Corpus y en las fiestas más señaladas de su Orden como las de San Francisco y Santa Clara y las prestasen a las restantes iglesias de Orduña.

${ }^{22}$ Otazu, A. y Díaz de Durana, J. R. 2008: 235 y 262-263. 
de la premisa. Sólo que, aunque puso mucho interés en acelerar la fundación, y aunque ésta acabaría respetando en buena medida sus deseos, la muerte le privó de ver erigido el colegio de Orduña, de comprobar la gestión de su legado por los jesuitas -que él dejó muy reglamentada-, y de llegar a recibir siquiera noticias sobre los primeros discípulos formados en sus aulas. Pero no adelantemos acontecimientos.

Las primeras gestiones de Urdanegui con la Compañía se iniciaron cuando menos en 1666, el mismo año en el que se hallaba embarcado en el proceso previo a la obtención del hábito de Santiago, y más necesitaba de sus paisanos para «construir» un pasado familiar hidalgo y honroso. De ello pudieron derivar precisamente ciertas promesas que el entonces capitán realizó a su ciudad natal y que luego pasado el tiempo no llegó a cumplir. Fue en esa fecha cuando desde Lima Juan acordó con los ignacianos una memoria que él mismo entregó al padre Felipe de La Paz, Procurador General de la Compañía en Roma, cuando éste se disponía a viajar a España. Según Armona, ahí se vio como ataron su negocio, atando bien a su benefactor. Todo se dispuso a favor de aquel y de los Provinciales de Lima y Castilla, que en ningún momento le dificultaron el patronato ni los anuales sufragios. ${ }^{23}$ No obstante, todo conduce a pensar que en principio Urdanegui se inclinó por confiar toda la tramitación a la Provincia jesuítica del Perú, lo que es comprensible a tenor de la influencia que la familia de su esposa tenía en la Orden, y en un intento por lo demás de reservar para sí mismo una importante capacidad de maniobra.

En esta primera memoria Urdanegui daba a conocer su deseo de establecer en Orduña un colegio con diez jesuitas, que debían encargarse de la formación y educación de los jóvenes de la ciudad y sus alrededores, pero también de confesar, predicar y asistir a los enfermos y moribundos. Ambas eran funciones que se ajustaban a la perfección a las consignas de la propia Compañía, para la que la enseñanza se convirtió desde sus primeros años en uno de sus dos ministerios más importantes ${ }^{24}$ junto con los sermones y la confesión, que siempre entendieron como un medio de consolidar clientelas..$^{25}$

${ }^{23}$ Salazar Arechalde, J. I. 2002:124-127.

${ }^{24}$ Martinez Naranjo, F. J. 2002. «Aproximación al estudio de las Congregaciones de Estudiantes en los Colegios de la Compañía de Jesús durante la Edad Moderna». Revista de Historia Moderna de la Universidad de Alicante, 20: 228-229.

${ }^{25}$ Burrieza Sánchez, J. 2004. «El poder de las palabras de la Compañía de Jesús en el Valladolid Moderno», en A. Alvar, J. Contreras y J. I. Ruiz (eds.), Política y Cultura en la época Moderna. Cambios dinásticos. Milenarismos, Mesianismos y Utopías: 795-802. Madrid: Universidad de Alcalá; Desde el principio, la legislación de la Compañía de Jesús consideró que la confesión era un ministerio prioritario para ser desarrollado por los jesuitas. Sin embargo, no sólo lo redujeron a su dimensión sacramental, sino que lo proyectaron hacia una dirección espiritual que sirvió para consolidar clientelas que apoyasen las fundaciones de sus colegios y acudiesen a sus sermones. Burrieza Sánchez, J. 2009 «Los jesuitas: de las postrimerías a la muerte ejemplar». Hispania Sacra 61, 124: 513-544.

Hispania Sacra, LXIV

129, enero-junio 2012, 309-343, ISSN: 0018-215-X, doi: 10.3989/hs.2012.011 
Con ese fin prometía un legado de 10.000 pesos de plata, la moneda internacional de la época ${ }^{26}$ destinados a la construcción de la iglesia y el colegio, más otros 30.000 que debían imponerse a censo para con sus réditos sustentar a los religiosos. Esta última operación se haría en principio en Ciudad de los Reyes, sobre fincas seguras a elección del Provincial del Perú, y a ser posible sobre las haciendas del colegio de San Pablo de Lima, u otro de la misma comarca, aunque para ello se necesitara redimir otro censo para imponer el nuevo. Pero en todo caso, éste no comenzaría a correr -y con él la obligación de pagar sus réditos- hasta que la fundación no estuviese garantizada, esto es, hasta que los jesuitas no entrasen en Orduña, y se iniciasen las obras de la iglesia y el colegio tras obtener las pertinentes licencias del Rey y del General de la Compañía, y el visto bueno del representante del propio Urdanegui.

Mientras tanto, y hasta que los 30.000 pesos no se impusieran sobre otra finca, el militar se comprometía a avalar esa renta -en principal y corridos- mediante la hipoteca de una de sus posesiones, en concreto una estancia y hacienda de ganado ovino que tiene realenga en San Marcos de Corpacancha, en los llanos de Bombón, que por aquel entonces le rentaba más de 5.000 pesos libres al año. De igual modo, remitiría a España en todas las Armadas el equivalente a los réditos previstos (1.500 pesos anuales). Según constaba en la misma memoria, la razón de situar esta renta en Perú era la mayor seguridad de las fincas respecto del trabajoso estado que tienen hoy todos los censos y fincas en España, aunque si el Provincial de Castilla y el General (así debió ser luego) consideraban conveniente que era mejor pasar a España los 30.000 pesos, y que había fincas o haciendas seguras donde imponerlos, remitiría la mitad en la primera Armada y los 15.000 restantes en la siguiente. De esa forma, se daba por entendido que con los 40.000 pesos prometidos cumplía con todo lo necesario para obtener el titulo de fundador, y los sufragios que acostumbraba la Compañía de Jesús. Eso sí, la iglesia debía dedicarse a la advocación de Jesús, María y José y someterse a las medidas, formas arquitectónicas y planos estipulados desde Perú y que traería en mano el Padre La Paz.

Ahora bien, consciente como era de la hostilidad que hacia la Compañía solían mostrar las otras comunidades religiosas, en particular de los franciscanos siempre reacios a la instalación de los jesuitas en territorio vasco, Urdanegui

${ }^{26} \mathrm{El}$ real de a ocho o peso indiano venía a pesar entre los 27 y los 27,5 gramos y el contenido de metal fino o ley (plata) debía alcanzar los 25,5 gramos. Su valor era de 272 maravedís. No tardó en convertirse en la primera moneda universal utilizada como instrumento de cambio en todo el mundo, pues aunque acuñada en las cecas peninsulares, especialmente en las de Sevilla y Madrid, y en las casas de Moneda de México, Santo Domingo, Lima, Potosí, Bogotá, Guatemala y Santiago de Chile, comerciantes que negociaban con regiones en las que existía una demanda de metales preciosos como el Báltico, Rusia, Levante, India y China la requerían, amén de usarse en el mercado interior americano hasta fines del siglo XVIII. García Guerra, E. M. 2006. «Itinerarios mundiales de una moneda supranacional: el real de a ocho o peso durante la Edad Moderna». Studia Histórica. Edad Moderna 28: 243. 
prometió otros 40.000 pesos destinados a otorgar rentas para misas, para los sacerdotes de la ciudad y el convento de San Francisco, y para diferentes obras pías dedicadas a dar estado a huérfanas, recaudar limosnas para pobres vergonzantes y mendicantes, y en general, para el beneficio público de Orduña. Pero seguía siendo condición imprescindible la previa fundación del colegio de los jesuitas, pues de no haberlo se malograrían todas estas obras pías y lo demás que está referido. El colegio acabó fundándose, pero según Armona estas partidas a favor del clero y la población locales nunca aparecieron.

Y es que todo parece indicar que en ciertos ámbitos los planes de Urdanegui sembraron dudas, incluyendo a la propia Compañía. En 1673 se carteaba con sus representantes en la Corte, extrañado por las reticencias que aquellos estaban produciendo a pesar de las ventajosas condiciones que él ofrecía. Su círculo de confianza lo componían: Sus primos Bernabé y Urbano de Urdanegui; El Maestre de Campo y caballero de la orden de Alcántara don Íñigo de Acuña y Castro, primer marqués de Escalona y mayordomo de la reina madre, hijo del que fuera corregidor en Cuzco y Potosí; Don Sebastián de Colmenares, secretario del conde de Lemos Pedro Antonio Fernández de Castro, virrey del Perú entre 1667 y 1672 y persona muy devota de los jesuitas entre quienes eligió confesor; El licenciado don Francisco Ortiz de Zárate y Salcedo, comisario del Santo Oficio y vicario de Orduña; Y finalmente, el capitán Juan de Ugarte, caballero de la orden de Santiago y sin duda el personaje más cercano a Urdanegui, a juzgar por el protagonismo que alcanzará en el tema que nos ocupa. Todos ellos con capacidad plena para representarle y gestionar cualquier asunto que le competiera, incluso si se trataba de cobrar en su nombre todo lo que por herencia u otra vía le perteneciera, ya en maravedís, pesos de oro y plata, barras, joyas y otras monedas, esclavos, mercaderías, ropa de casa, balumen, semillas y frutos de la tierra y demás bienes muebles, raíces y semovientes. ${ }^{27}$

Pues bien, al transmitirles sus planes sobre la fundación en Orduña Urdanegui había cambiado algunos postulados. No en vano habían transcurrido siete largos años, en los que debieron mediar presiones de distinto signo, en particular en la Provincia Jesuítica de Castilla. Ahora ya no debían ser diez, sino catorce los religiosos (entre ellos uno destinado a las primeras letras, otro Gramática Latina y un tercero Teología Moral). Religiosos llamados a ocuparse también de cubrir por turno de a dos las misiones a celebrar tres o cuatro veces al año en los alrededores de la ciudad, y muy particularmente en el Valle de Gordejuela, donde se hallaba la torre, casa y solar de los Urdanegui.

Pero había aún otro cambio más sustancial en las nuevas disposiciones. Algo o alguien debieron hacerle entender que el manejo desde el Perú no gustaba

${ }^{27}$ AHN. Clero-Jesuitas. Leg. 184. Exp. 1, sin foliar, [Carta de don Juan de Urdanegui fechada en Lima el 30 de noviembre de 1673], y Exp. 2, sin foliar, [Carta de poder firmada por don Juan de Urdanegui en Ciudad de Los Reyes el 7 de diciembre de 1674]. 
en la Provincia de Castilla, y que era ese el motivo por el que se demoraba la fundación. De modo que mantuvo el legado en su totalidad pero se avino a que todos los trámites se llevaran a cabo en España. Se resignaba a enviar a Sevilla, a su costa y riesgo, los 40.000 pesos de plata libres de costas, gastos y averías. Lo haría en dos tandas de 20.000, aprovechando las dos primeras armadas de galeones que zarpasen desde Perú, la primera de las cuales se esperaba para ese mismo año a cargo del general Nicolás de Córdoba. Una vez en la capital hispalense, los dineros se conducirían a la Corte a manos de su hombre de confianza, el capitán Juan de Ugarte, para su posterior entrega a la Compañía de Jesús. El dinero sería completado con diversos objetos de plata, en poder del mismo capitán, que tenían como destino la futura iglesia del colegio de Orduña. ${ }^{28}$ Ugarte, en representación del militar, y el padre Francisco Marcos de Chaves por la Compañía, serían los encargados de iniciar los trámites de la fundación.

De ese modo buscaba el general una nueva oportunidad para ganarse en vida el reconocimiento de sus paisanos. No cabe dudar en él una intencionalidad propia de aquellos tiempos: Asegurar la educación en el contexto de una determinada ideología para los hijos de Orduña, y el reconocimiento social para él y los suyos. Era la razón por la cual dejaba bien sentado que como fundadores y patronos debían aparecer él mismo y su esposa Constanza, y a su muerte sus hijos y descendientes o, en su falta o ausencia, el señor de la Casa de Urdanegui. Le pertenecía el título por aquel entonces a su primo don Bernabé de Urdanegui, vecino de Bilbao y del valle de Gordejuela, ${ }^{29}$ hijo del hermano mayor de don Juan, que recientemente había reconstruido la casa-torre de la familia con su propia hacienda, sacándola del empeño en que estaba. ${ }^{30}$ Recuérdese que en aquella sociedad sacralizada y de privilegios, ser patrono de una fundación no sólo estaba muy bien considerado, sino que garantizaba la salvación del alma, para glorificación propia, de la familia y de los antepasados. ${ }^{31} \mathrm{Y}$ don Juan, sin duda conocedor de lo que las Constituciones de Ignacio de Loyola habían dejado señalado al respecto, reclamaba para sí y los suyos el trato, las atenciones de carácter espiritual, y las preeminencias y privilegios que según aquellas los jesuitas debían guardar a sus fundadores.

Con todo, Urdanegui seguía imponiendo condiciones, que denotan que se movía con cierta inquietud y sobre todo con premura, pues comprometía a la Compañía a adquirir los bienes necesarios para poner en marcha el colegio an-

\footnotetext{
${ }^{28}$ Entre ellos un frontal de altar en piezas «muy rico», más tres lámparas y una custodia sobredorada. Se trataba de alhajas de alto valor. El frontal de plata tenía un peso de 84 marcos y 3 onzas, las lámparas 180 marcos y 5 onzas y la custodia 5 marcos y 1 onza. AHN. Clero-Jesuitas. Leg. 184. Exp. 22, f. $17 \mathrm{r}$.

${ }^{29}$ AHBBVA. Fondo Jesuitas. Leg. 2. Carp. 4, f. 1r. y ff. 2r-2v.

${ }^{30}$ AHN. Clero-Jesuitas. Leg. 184. Exp. 22, ff. 19v-20r.

${ }^{31}$ Burrieza Sánchez, J. 2003. «La recompensa de la eternidad. Los fundadores de los colegios de la Compañía de Jesús en el ámbito vallisoletano». Revista de Historia Moderna 21: 29-56.
} 
tes incluso de que los dineros llegasen a la capital hispalense. En particular ponía énfasis en que el dinero se invirtiese adecuadamente. En su opinión, su legado, puesto en Sevilla y en la Corte con el creçe de vellón a la plata vendrán a ser 80.000 ducados $^{32}$ y confiaba en que la buena administración de la Compañía aseguraría un rendimiento aún mayor. Por ello comprometía al Provincial de Castilla la Vieja a comprar haciendas de calidad, capaces de reportar rentas abundantes y rápidas, suficientes para afrontar por sí solas la construcción de la iglesia y el colegio, mantener a los padres y asegurar sus tareas docentes. La consigna era que el principal de los 40.000 pesos siempre ha de estar en pie y permanente, ${ }^{33}$ lo cual no le parecía difícil respecto al poco costo que tiene la tierra en el paraxe de la dicha fundación. ${ }^{34}$

Si bien decía respetar la libre disposición del Provincial de Castilla, recomendaba colocar total o parcialmente el capital en renta de juros o en censos de buena calidad, situación y paraje "y no de los baratos y que tienen dilatadas situaciones», siempre con la mirada puesta en el provecho de los mismos padres que «a muy poca costa, cojeran el pan y vino necesario para el gasto y sustento del dicho colexio, teniendo algunas tierras y viñas que agregadas a otras se pueda conseguir lo referido con mayor facilidad». ${ }^{35}$ Eso sí, ante el menor contratiempo los dineros se guardarían a buen recaudo a la espera de una mejor inversión y, de malograrse la fundación, el legado y sus rentas revertirían a la familia. ${ }^{36}$

A pesar de su insistencia la fundación no veía la luz. Por una carta fechada en noviembre de 1676, Urdanegui confirmaba al Ayuntamiento de Orduña sus buenas intenciones, y recordaba su vieja promesa de que una vez fundado el

${ }^{32}$ AHBBVA. Fondo Jesuitas. Leg. 2. Carp. 4, f. 3r. En 1680, el gobierno de Carlos II, aprovechando que se habían reiniciado las llegadas de plata, ordenó retirar grandes cantidades de vellón de la circulación, lanzándose nuevas acuñaciones de reales en plata -aunque con un $20 \%$ menos de plata-con el fin de que se abandonaran los reales antiguos, de tal manera que la moneda de plata recuperó su papel en la vida cotidiana. La estabilidad monetaria fue total entre 1680 y 1700.

${ }^{33}$ AHN. Clero-Jesuitas. Leg. 184. Exp. 3, sin foliar, (año 1675).

${ }^{34}$ AHBBVA. Fondo Jesuitas. Leg. 2. Carp. 4, ff. 2r-2v; Sin duda tenía prisa por acelerar los trámites puesto que ya en su carta de 1673 recomendaba a la Compañía iniciar la compra de fincas antes de que llegase el dinero, ofreciendo no obstante éste como garantía "pues se necesita tiempo y en el ynter que llega la plata se podrá ajustar debaxo de condiçion que se dara satisfaccion en la dos primeras llegadas de galeones a España». AHN. Clero-Jesuitas. Leg. 184. Exp. 1, sin foliar.

${ }^{35}$ AHBBVA. Fondo Jesuitas. Leg. 2. Carp. 4, f. 3v.

${ }^{36} \mathrm{Si}$ por alguna razón las rentas llegaban a redimirse o a venderse los bienes adquiridos por el colegio, el dinero debía encerrarse en el arca bajo tres llaves «y de alli no se pueda sacar en poco ni en тиcha cantidad si no fuere para bolberlo a emplear en hacienda buena y redictuable». Pero si por algún accidente «pensado o no pensado» después de todo la fundación no se llevase a cabo, todos los bienes adquiridos con el legado y su renta debían revertir a Urdanegui y su esposa o a sus descendientes, «pues cesando el buen proposito que era la educación de los hijos de la ciudad de Orduña y los alrededores, todo debía volver a su tronco y los frutos dellos para que los gozen como vienes propios de los dichos fundadores y sus descendientes». Ibídem, f. 4r.

Hispania Sacra, LXIV

129, enero-junio 2012, 309-343, ISSN: 0018-215-X, doi: 10.3989/hs.2012.011 
colegio enviaría otros 40.000 pesos para la toma de estado de varias muchachas de la ciudad. ${ }^{37}$ Pero sólo un año y medio después, en marzo de 1678, las autoridades municipales decidieron convocar a concejo abierto a los vecinos para tratar sobre la cuestión. Una fórmula de la que, por cierto, la Compañía de Jesús solía huir como alma que se lleva el diablo, pues solía serle desfavorable, como tuvieron oportunidad de comprobar repetidamente en Vitoria y en Bilbao desde la segunda mitad del siglo XVI. ${ }^{38}$ En esta ocasión tuvieron más suerte, y por voluntad de todos se acordó acoger a los jesuitas en Orduña, decisión que fue ratificada por las autoridades seguramente el 18 de octubre de ese mismo año de $1678 .{ }^{39}$ A ese acto, celebrado en la casa consistorial de Orduña, asistieron el Provincial de Castilla la Vieja Pedro Jerónimo de Córdoba, que actuaba en nombre de su General Juan Pablo de Oliva, y los dos cabildos, secular -se dice que en representación del propio Urdanegui- y eclesiástico, de la ciudad de Orduña.

Lo interesante es que una vez que la primera mitad del legado llegó a Sevilla, las partes comprometidas se reunieron para atar algunos cabos sueltos mediante unas Capitulaciones que se firmaron a tres bandas: por parte de la Compañía el rector del colegio de Bilbao Juan de Elizondo y el padre Jerónimo de San Juan residente en el mismo; En nombre de los cabildos el vicario de Orduña y Comisario de la Inquisición don Francisco Ortiz de Zárate y Salzedo, decano de los curas y beneficiados de las parroquias; y, en representación del fundador, su primo Bernabé señor de Urdanegui. ${ }^{40}$ En ellas se aceptaban en esencia las disposiciones de don Juan, pero se perfilaban algunas exigencias, en un claro intento por evitar que la entrega del legado a la Compañía -y más en concreto a la Provincia de Castilla- se demorara. Y en parte era lógico que así ocurriera, a tenor de lo que con frecuencia ocurría en casos como éste. Ha de tenerse en cuenta que la actividad crediticia de los jesuitas fue habitual hasta 1767, y que en ella solían aprovechar incluso las remesas de dinero que se traían a España desde Indias en las que ellos actuaban como intermediarios. La Procuraduría General de Indias en Sevilla -que solía encargarse de recibir las remesas desde América- o la de

\footnotetext{
${ }^{37}$ AHN. Clero-Jesuitas. Leg.184. Exp. 22, f. 3r, [Carta de Urdanegui fechada en Lima el 24 de noviembre de 1676].

${ }^{38}$ Porres Marijuán, R. 2012. «Maniobras políticas y convulsión social en la aproximación de los jesuitas al País Vasco en el siglo XVI», en Los jesuitas: religión, política y educación, siglos XVI-XVIII. Madrid: Polifemo (en prensa).

${ }^{39}$ Malaxechevarría sitúa ese acuerdo el día 18 de octubre pero de 1676 , lo cual no parece probable puesto que en ese caso no hubiera tenido razón de ser la carta de Urdanegui al Ayuntamiento en noviembre de 1676. Malaxechevarría, J. 1926. La Compañía de Jesús por la instrucción del País Vasco en los siglos XVII y XVIII: 109-110. San Sebastián. En el mes de marzo de 1678, y fallecido ya el padre La Paz, el Ayuntamiento había contactado con el nuevo Procurador Alonso Gómez, por entonces en Roma aunque residía en Madrid, para que abordara las diligencias oportunas ante el General de la Compañía y ante el monarca. AHN. Clero-Jesuitas. Leg. 184. Exp. 22, ff. 2r-v.

${ }^{40}$ Ibídem, ff. 17v-18r.
} 
Madrid, empleaban con frecuencia el dinero que se les había confiado para su transporte, tanto si iba destinado a su orden como si no, en conceder créditos, ya a la Corona, ya a particulares. De ese modo, los procuradores dilataban a veces incluso durante 30 y 40 años la entrega a sus destinatarios finales. ${ }^{41}$

Pues bien, en este caso se hacía responsable al propio Urdanegui de que eso no ocurriera, dándosele un plazo de tres meses para entregar al Provincial en Castilla la Vieja la mitad del legado, que tras su llegada a la capital hispalense se hallaba en manos de uno de sus poderhabientes, el marqués de Escalona don Iñigo de Acuña y Castro. Al mismo tiempo, se le apremiaba a acelerar la entrega de la otra mitad, comprometiéndole a pagar a los jesuitas los intereses de demora a razón del 5\% al año, hasta que el dinero se depositase en Sevilla. A cambio, una vez que se entregasen los 40.000 pesos la Compañía consideraría a Urdanegui y a sus herederos libres de cualquier otra carga para siempre jamás, comprometiéndose por su parte a mantener ilesos los 40.000 pesos, siguiendo la voluntad del fundador.

También existen noticias acerca de otro capitulado firmado entre la Compañía de Jesús y los cabildos secular y eclesiástico de Orduña -de él se tratará después- a raíz de un viaje efectuado a la ciudad vizcaína por el rector del colegio de San Sebastián, Francisco de Alesón, enviado por el Provincial de Castilla. ${ }^{42}$ Entre unas cosas y otras, éste no decidiría la ubicación definitiva del colegio hasta 1680. La primera piedra se colocó según algunos autores en ese mismo año, y según otros en 1683. Urdanegui ya había muerto -posiblemente el 16 de noviembre de $1682-$ no sin antes hacer a los jesuitas una última donación. Según apuntan Otazu y Díaz de Durana, ${ }^{43}$ en los últimos días del verano de 1681, ya con 62 años, otorgó testamento no lejos de Lima. Había hecho venir a sus íntimos, entre los cuales se hallaba el capitán Diego de Iurretauria, vizcaíno de Elorrio, y Juan de Oriamuño, propietario de navíos en Nueva España, ${ }^{44}$ y tras hacer inventario de todos los objetos de plata que tenía en poder de los franciscanos de Orduña, dio orden de entregarlos al rector de los jesuitas de la ciudad

\footnotetext{
${ }^{41}$ En el importante papel que la Iglesia jugó en la Carrera de Indias, especialmente en las remesas enviadas desde América a España, destacaron tres órdenes que intervinieron en el envío de casi el 80\% del dinero traído desde las Indias por aquella: los franciscanos, los mercedarios y, especialmente, los jesuitas, primero por lo temprano y lo regular de sus envíos, que se inician a finales del siglo XVI y no finalizan hasta su expulsión en 1767, y lo segundo por la elevada cuantía de sus remesas que en el siglo XVIII alcanzaron el 1\% de todo el dinero registrado que viene de América. López Martinez, A. 2000. «Los jesuitas y su intermediación financiera en la Carrera de Indias» en Bernal, A. M. (ed.): 752 y 764.

${ }^{42}$ AHN. Clero-Jesuitas. Leg. 184. Exp. 22, ff. 17v-18r. y ff. 22v-28r.

${ }^{43}$ Otazu, A. y Díaz de Durana, J. R. 2008: 264-265.

${ }^{44}$ En 1692 Juan de Oriamuño pera propietario del navío Jesús, María y José de entre 550 y 600 toneladas, procedente del astillero Realejo en la costa de Nueva España y que vendió a la Real Armada. León Sáenz, J. 2009. «Los astilleros y la industria marítima en el Pacífico americano. Siglos XVI-XIX». Diálogos. Revista electrónica. Universidad de Costa Rica 10: 1.
} 
«donde servirán para el culto divino», a condición de que los prestaran al resto de las iglesias y al convento de Santa Clara cuando fuese menester.

Cuando un año después le sobrevino la muerte, su ruptura con los franciscanos, y por tanto con la capilla de los vizcaínos de Aránzazu, se haría también patente ante los limeños. Su cuerpo se expuso en la capilla que la Congregación de los Seglares de Nuestra Señora de la 0 tenía en el colegio jesuítico de San Pablo, y no en la de Aránzazu, y allí se exhibió, tendido en un ataúd sobre un paño negro a ras de suelo y con cuatro velas alrededor, amortajado con el hábito de la Compañía y cubierto el féretro con el manto de la Orden de Santiago. No pudo ver culminada su obra, pues las obras de Orduña no se terminaron hasta 1694, aunque cuando menos desde 1689 se estableció en esa ciudad una pequeña comunidad de jesuitas dedicada a la enseñanza bajo la batuta de su primer rector el padre Martín Lazcano. La iglesia, construida en los años ochenta junto al colegio siguiendo la traza de Santiago Raón, cambió la morfología medieval de la ciudad e inauguró el barroco en Vizcaya. En ella serían depositados los restos del fundador y de su esposa, fallecida en Lima en 1712.

\section{LA CONFIGURACIÓN DEL PATRIMONIO: FINCAS, JUROS Y CENSOS}

Al margen de otras consideraciones, al indagar sobre el patrimonio de los jesuitas del colegio de Orduña se han de tener en cuenta tres cuestiones importantes: La primera, que la Compañía siguió bastante a rajatabla las disposiciones del fundador en lo concerniente a inversiones; La segunda, que en comparación con otros centros de mayor tradición apenas contaron con setenta y ocho años (1689-1767) para acumular propiedades, en todo caso los suficientes como para mostrar diferencias respecto a otros centros contemporáneos como Loyola o Lequeitio; La tercera, que las inversiones se vieron condicionadas por las cláusulas que los cabildos secular y eclesiástico impusieron antes de aceptar la fundación, ${ }^{45}$ de las cuales algunas se ocupaban de regular la adquisición de bienes. Entre estas últimas, quizá la más importante, la que impedía a los jesuitas hacerse con propiedades dentro de la ciudad y del valle alavés de Arrastaria considerado como su término, salvo lo necesario para levantar la planta de la iglesia, casa y oficinas del colegio, 50 aranzadas de tierra para huerta destinada a alimentarlo, más otras 200 aranzadas para servicio de los propios religiosos que podían dedicarse a viñedo o a cualquier otra granjería.

El Provincial Pedro Jerónimo de Córdoba aceptó esas restricciones y hasta se comprometió a no disponer, recibir, ni comprar ninguna otra clase de bienes raíces, hacienda de campo, ni de pan llevar, ni viñas, ni casas, huertas, molinos, ruedas, montes, ni en propiedad ni en usufructo, más allá de lo señalado. Tam-

\footnotetext{
${ }^{45}$ AHN. Clero-Jesuitas. Leg. 184. Exp. 22, ff. 22v-28r.
} 
bién renunció a imponer censos de cualquier tipo, en la ciudad, en su jurisdicción, y en el valle. Si algo les llegaba a través de donaciones, testamentos u otras vías, debían desprenderse de ello en el plazo de un año, con la excepción de los juros de las aduanas «porque de estos pueden comprar quantos quisieren». Eso sí, durante ese plazo serían obligados a pagar los diezmos y primicias de todos los frutos, ya de las tierras, ya del ganado, de la misma forma que debían pagarlos en caso de disfrutar de bienes en arrendamiento. Sólo se les eximía de los diezmos y primicias de lo que cogiesen para su sustento, tanto en la huerta propia como a través del ganado.

\section{Cuadro 1}

PROPIEDADES DEL COLEGIO DE ORDUÑA EN $1767^{46}$

\begin{tabular}{|l|c|c|c|c|}
\hline BIENES & $\mathbf{N}^{\mathbf{0}}$ & $\begin{array}{c}\text { VALOR EN / } \\
\text { RS }\end{array}$ & $\begin{array}{c}\text { \% SOBRE } \\
\text { EL TOTAL }\end{array}$ & $\begin{array}{c}\text { RENTA ANUAL / } \\
\text { RS }\end{array}$ \\
\hline Casas y caserías & 4 & 153.136 & $17,9 \%$ & 4.070 \\
\hline Heredades, huertas y viñas & 10 & 16.223 & $1,9 \%$ & ----- \\
\hline Juros & 1 & 48.996 & $5,73 \%$ & 5.748 \\
\hline Censos & 15 & 635.235 & $74,41 \%$ & 10.303 \\
\hline TOTAL & & $\mathbf{8 5 3 . 5 9 0}$ & $\mathbf{9 9 , 9 4 \%}$ & \\
\hline
\end{tabular}

Elaboración propia

Como se puede comprobar por el cuadro adjunto, en el momento de la expulsión la deuda pública y privada componía el $80 \%$ del patrimonio de los jesuitas de Orduña, mientras que las fincas rústicas y urbanas apenas alcanzaban el 20\% restante. Quiere ello decir que su interés se centró en el crédito y no en los inmuebles, particularmente en las caserías, a diferencia de otros colegios que la Compañía fundó en el País Vasco por la misma época. El de Loyola, erigido en 1689, había llegado a acumular hacia 1761 entre cuarenta y seis y cincuenta y nueve caserías, además de algunas fraguas, molinos, posadas y tejerías, repartidas por toda Guipúzcoa (Azpeitia, Azcoitia, Albístur, Andoain, Zumaya, Guetaria, Deva, Motrico, Oyarzun, Rentería, Irún, Eibar) y hasta en el mismo Bilbao. Todo ello por un valor de casi dos millones y medio de reales que producían una renta anual de algo más de treinta y un mil. ${ }^{47}$

Algo parecido, aunque en menor volumen, había acontecido con el colegio de la localidad vizcaína de Lequeitio, donde la Compañía se instaló también en

${ }^{46}$ Ibídem. Expedientes 16, 18, 26, 27 y 30.

${ }^{47}$ El valor exacto las propiedades ascendía a 2.466.948 reales, y producían una renta anual de 31.241. Fernández de Pinedo, E. 1974. Crecimiento económico y transformaciones sociales del País Vasco, 1100/1850: 312. Madrid: Siglo XXI Editores.

Hispania Sacra, LXIV

129, enero-junio 2012, 309-343, ISSN: 0018-215-X, doi: 10.3989/hs.2012.011 
1689. Según narraba en 1750 uno de los beneficiados de su cabildo eclesiástico, aquella había adquirido hasta entonces doce caserías en propiedad sólo en su dezmatorio, e incluso tenía prendadas otras tres, cuando en el momento de la fundación apenas contaba con cuatro en prendas. Y lo peor era que el fenómeno iba a ir a más, ya que los jesuitas habían logrado una declaración del rey en virtud de la cual en las caserías de su propiedad sólo habían de pagar «de veinte uno» en concepto de diezmo. Estaba seguro de que si seguían adquiriendo más fincas, el diezmo a percibir por el cabildo menguaría cuando menos a la mitad. De ahí que lo que en su exposición apenas se iniciaba como una mera queja ante el fisco real, acabase en un feroz ataque contra los regulares porque, decía, «juegan con tal mañosidad en la adquisición [...] que en viendo a algún casero empeñado, y especialmente siendo de este mi dezmatorio, le alargan y dan todo el dinero necesario a censo, en cuyo principal, que suele ser de monta, y réditos devengados, si es descuidado dicho casero en satisfacer anualmente, vienen a alzarse con toda la casería». ${ }^{48}$

Claro que, si comparamos el caso de Orduña con otras localidades de fuerte impronta mercantil como ella misma, las diferencias no son tan sustanciales. Al contrario, en el núcleo aduanero por excelencia, Vitoria, donde tuvieron muy serias dificultades para asentarse, los jesuitas se dedicaron abiertamente al crédito, antes incluso de llegar a fundar en 1751. En 1744, cuando apenas residían en la ciudad dos padres, declaraban censos por valor de 259.094 reales contra diversos particulares e instituciones de la ciudad, pero también contra las instituciones provinciales de Álava y algunas villas alavesas (Salvatierra) y guipuzcoanas (Placencia y Azpeitia). ${ }^{49}$ Sin embargo, apenas disponían de cuatro casas y un pajar que les habían sido donados por su benefactor, el general don Juan Francisco Manrique de Arana y que apenas les rentaban 1.000 reales anuales.

Si nos acercamos a Bilbao, en porcentajes los datos son similares a los de Orduña. La deuda pública y el crédito procuraban el $77 \%$ (45.338 reales) de sus rentas a los jesuitas bilbaínos, y los bienes inmuebles apenas el 23\% restante. De hecho, el colegio bilbaíno de San Andrés fundado a comienzos del siglo XVII, decía poseer en 1767 media casería en Baracaldo y dos porciones de monte en la anteiglesia de Echano, de los que se cobraban 98 reales al año. Ni siquiera en el ámbito urbano sus propiedades pasaron de discretas. Ocho casas, lonjas y tejavanas en el núcleo bilbaíno, producían una renta de poco más de 13.000 reales anuales.$^{50}$ En total, unas rentas de apenas 13.300 reales, por el conjunto de unos bienes inmuebles valorados en algo más de 628.000.

\footnotetext{
${ }^{48}$ Ibídem: 311.

${ }^{49}$ AHN. Clero-Jesuitas. Leg. 189. Exp. 3, f. 21.

${ }^{50}$ AFSSV. Fondos del Parlamento Vasco. 01065.1.1/2.
} 
Las tres casas y la casería de las que eran propietarios los jesuitas de Orduña en 1767 alcanzaban un valor de 153.136 reales y les suponían unas rentas anuales de $4.037 .{ }^{51}$ De ellas sólo una se hallaba en la propia ciudad, y era fruto de la donación del fundador don Juan de Urdanegui. Se trataba de una pequeña vivienda «con porción de tierras y viñas accesorias a ella» situada en la calle Burgos y valorada en 4.899 reales y medio. En otras palabras, se trataba de la hacienda que sus padres habían levantado tras contraer matrimonio. La llevaba en arrendamiento Blas del Campo, que pagaba por ella una renta de 150 reales por la casa y la viña y 7,5 fanegas de trigo por las tierras. En realidad menos, porque al ser en origen propiedad del fundador se hallaba gravada con algunas cargas familiares. ${ }^{52}$ No obstante, su tesoro más preciado lo componían una casa principal llamada Endayaencoa sita en la calle Mayor de San Sebastián, y otra casa horno en su trasera, en la calle Ballena, que hacia 1762 habían comprado los jesuitas de Orduña a doña Mariana Mañeras Teming, vecina de Madrid, por 96.000 reales. Rentaban al año poco más de 3.359 reales.

Fue también mediante compra como los padres de Orduña se hicieron con una casería situada en el enclave alavés de Aloria, muy próximo al valle de Arrastaria, nada ajeno a los Urdanegui como se ha visto, aunque fuera por parte de la familia materna los Inoso. ${ }^{53}$ Situada en una ladera al este de Orduña, en su época se hallaba en un cruce de caminos de herradura, olvidados hoy, que abría el valle hacia Lezama en el extremo oriental de Ayala, y hacia Urcabustaiz en ruta a la Llanada alavesa. Según el licenciado Gil, en 1556 Aloria tenía 15 vecinos, y tanto diezmos como primicias se abonaban en trigo, vino y corderos, aparte de ciertas cantidades de dinero. En 1786 tenía unos 17 o 18 vecinos, todos labradores e hidalgos, y su mayor producción, como en el siglo XVI, seguían siendo los granos y el chacolí. La casería, con su lagar, cabaña, huerta y tierras accesorias, tenía una extensión de 16 aranzadas y 5 pértigas, que los jesuitas habían comprado por 18.237 reales -el mismo precio en el que será tasada en 1767- y rentaba al año 396. Esta propiedad de Aloria marca cierta distancia con otras comunidades jesuíticas como la de Bilbao, y demuestra que la fuer-

${ }^{51}$ En realidad eran 4.070 reales y 12 maravedís pero las cargas familiares (misas y cera) con las que se hallaba gravada la casa de Orduña que había pertenecido al fundador del colegio se detraían de la renta, de ahí que la cantidad exacta en dineros fuera de 4.037 reales.

${ }^{52}$ De esta manera, a la renta se le detraían 33 reales de forma que la renta global que pagaba por la propiedad era de 282, en lugar de los 315 estipulados: 16 reales de limosna por dos misas cantadas que cada año debían celebrarse en el convento de San Francisco en la capilla de San Antonio perteneciente a los herederos del fundador, y otros 17 reales por el valor de dos libras de cera amarilla que se debía poner en la misma capilla todos los días festivos. A esta carga se le añadía una fanega de pan cocido de ofrenda en la capilla de San Antonio del convento de San Francisco de Orduña (1 f. trigo). Así pues, la carga era de 33 reales y una fanega de trigo al año. AHN. Clero-Jesuitas. Leg. 184. Exp. 26, (año 1767).

${ }^{53}$ No obstante, cierto documento se señala que las tierras pertenecientes a la huerta del colegio y a la casería de Aloria alcanzan en total 284 aranzadas con 89 pértigas lo que tal vez pueda indicar que la hacienda hubiese sido adquirida en parte mediante compra y en parte por herencia recibida de los Inoso. AHN. Clero-Jesuitas. Leg. 184. Exps. 30 y 26, sin foliar.

Hispania Sacra, LXIV

129, enero-junio 2012, 309-343, ISSN: 0018-215-X, doi: 10.3989/hs.2012.011 
te impronta mercantil de la ciudad de Orduña no les impidió disponer de una hacienda en la que no faltaron los bienes rústicos ni el ganado. En el momento del extrañamiento disponían de 20 carneros en la propia ciudad aduanera, que fueron vendidos por 880 reales.

Por lo demás, el grueso de las fincas rústicas se hallaba en Orduña. Cabe pensar que procedían de la donación del propio fundador y de las compras que las cláusulas fundacionales les permitían. La huerta inmediata al colegio en el término conocido como el Castillo era la joya en lo que a tierra se refiere, siendo valorada en algo más de 4.811 reales. De unas 11 aranzadas con cerca de pared, y dos carreras de viñas emparradas y setenta árboles frutales de distinto género, abastecía de fruta y cabe pensar que de hortalizas a la propia comunidad ignaciana. También de vino, junto a las otras tres viñas que completaban 20 aranzadas, lo que suponía prácticamente el $12 \%$ del total de las 170 aranzadas de su propiedad, mientras que el $88 \%$ restante se destinaba a otras granjerías.

\section{Cuadro 2}

HEREDADES LOCALIZADAS EN ORDUÑ ${ }^{54}$

\begin{tabular}{|l|c|r|c|c|}
\hline & \multicolumn{2}{|c|}{$\begin{array}{c}\text { MEDIDAS } \\
\text { ARANZADA } \\
\text { PERTIGA }\end{array}$} & $\begin{array}{c}\text { VALOR REAL } \\
\text { /ARANZADA }\end{array}$ & $\begin{array}{c}\text { VALOR } \\
\text { TOTAL EN } \\
\text { REALES }\end{array}$ \\
\hline Viña. Término de Echávarri & 2 & 16 & 154 & 328,20 \\
\hline Heredad. Arroyo del egido real & 6 & 9 & 77 & 478,05 \\
\hline Viña. Término de San Mamés & 4 & 24 & 77 & 348,30 \\
\hline Heredad. Término de Urianana & 34 & 9 & 30 & 1.027 \\
\hline Campo. Término de Margondo & 8,5 & & 20 & 170 \\
\hline $\begin{array}{l}\text { Heredad. Término de Santa } \\
\text { Clara }\end{array}$ & 38,5 & & 100 & 3.850 \\
\hline Viña. Término de Rondina & 14 & 15 & 60 & 862,02 \\
\hline Heredad. Término de Landata & 35 & 38 & 77 & 2.761 \\
\hline Heredad. Término de Landata & 17 & 26 & 90 & 1.586 \\
\hline $\begin{array}{l}\text { Huerta (cercada con pared). } \\
\text { Término de El Castillo. }\end{array}$ & 11 & & 200 & $4.811,17^{55}$ \\
\hline TOTAL & $\mathbf{1 7 0}$ & $\mathbf{1 3 7}$ & & $\mathbf{1 6 . 2 2 3}$ \\
\hline
\end{tabular}

${ }^{54}$ Ibídem. Exp. 16 (tasación del año 1769). ARANZADA en Castilla = 4.472 m cuadrados; PERTICA 0 PERTIGA= algo más de 7 metros.

${ }^{55}$ Se tasa cada aranzada a 200 reales de vellón con lo que el contenido y la huerta se tasa en 2.200 reales. Sin embargo se hace también una tasación de la cercadura con pared en 2.611 reales y 17 maravedís con lo cual el valor global de la propiedad asciende a 4.811 reales y 17 maravedís. Ibídem. Exp. 16, (tasación del año 1769). 
No obstante, su especialidad fueron las inversiones en deuda en nombre del propio colegio, con preferencia hacia los censos sobre los juros. A pesar de la libertad que sobre ello habían recibido de los cabildos a la hora de firmar las capitulaciones, cuando analizamos las rentas de los jesuitas de Orduña no encontramos juros sobre las aduanas, aunque es cierto que el crédito, más aún que la explotación de propiedades rústicas, fue su principal actividad económica en la ciudad. Y es extraño, porque las comunidades eclesiásticas vascas solían invertir en este tipo de deuda. Entre los titulares de juros situados sobre la renta de las aduanas de Vitoria en 1682, esto es, en las fechas en las que se fundó el colegio de Orduña, aparecían diversas comunidades religiosas como los conventos de la Encarnación de Bilbao, Santa Trinidad de Oñate, Nuestra Señora de la Concepción en Eibar, San Francisco y San Agustín de Mondragón, Santa Trinidad de Vergara, San Francisco de Tolosa, Santa Clara de Zaráuz, Santo Domingo y San Francisco de Vitoria, la parroquia de San Pedro de Vitoria y los cabildos eclesiásticos de Eibar y Bilbao. ${ }^{56}$ Es posible que por entonces aquellos juros no dieran demasiado juego. Se cobraban irregularmente y cada vez producían menos. ${ }^{57}$ Pero, a fin de cuentas, era el mal que afectaba a los juros en general, como también a los censos. Y más aún desde los tiempos de Felipe IV por vía de las medias anatas, que tanto impacto tuvieron sobre los colegios de la Compañía de Jesús de la Provincia de Castilla, que en 1654 se quejaban de que se les habían tomado ya por ese concepto 500.000 ducados, de los que no se les había dado ninguna satisfacción. ${ }^{58}$

En adelante fue cada vez menos rentable invertir en ellos -de ahí las prevenciones del fundador que se han señalado con anterioridad-, y más en el caso de los laicos ${ }^{59}$ aunque López Martinez indica que a pesar de esa depreciación general los únicos que pudieron sacar rentabilidad a los juros fueron las instituciones eclesiásticas, gracias a los privilegios y exenciones que tenían ${ }^{60}$ Ya

\footnotetext{
${ }^{56}$ Angulo Morales, A. 1995. Las puertas de la vida y la muerte: la administración aduanera en las provincias vascas (1690-1780):168. Bilbao: Servicio Editorial de la Universidad del País Vasco/EHU.

${ }^{57}$ De ello se quejaban en la localidad vizcaína de Lezama, muy próxima a Orduña, donde en 1637 fray Agustín de Guinea dejó un importante legado en censos y juros destinado a limosnas para pobres, dotación de doncellas huérfanas y becas para estudiantes. De ellos, 4.035 ducados de principal correspondían precisamente a un juro sobre las aduanas de Orduña que rentaban al año 202 ducados. Pues bien, en 1690 se quejaban de que, además de cobrarse irregularmente, cada año producía menos. Catalán Martínez, E. 2000. El precio del purgatorio. Los ingresos del clero vasco en la Edad Moderna: 181. Bilbao: Servicio Editorial de la Universidad del País Vasco/EHU.

${ }^{58}$ Domínguez Ortiz, A. 1964. Política y hacienda de Felipe IV: 324. Madrid: Ediciones Pegaso.

${ }^{59}$ Fernández de Pinedo, E. 2000. «La deuda pública y los juristas laicos, 1550-1650», en A. M. Bernal, A. M. (ed.): 807-824.

${ }^{60}$ Según este autor, la participación de los conventos en la deuda pública en el siglo XVI fue bastante reducida, quizá porque la compra de tierras les resultaba más atractiva. Esta situación empezaría a cambiar a comienzos de la centuria siguiente. López Martínez, J. L.1992. «Los juros eclesiásticos. Participación de los conventos andaluces en la deuda pública castellana». Revista de Historia Económica, 3: 438; De hecho, los colegios de los jesuitas andaluces tenían en 1663 en renta de juros 12.044.927
} 
con los Borbones, los descuentos aplicados por la Corona en 1703 y 1710 y disposiciones posteriores afectaron poco a los juros de la Compañía, pero ésta no pudo sustraerse a la ley de 1727 que supuso la rebaja del interés del 5 al 3\%. En los años sucesivos la deuda continuó por la pendiente de la desvalorización y más desde que la Junta de teólogos y juristas que Fernando VI nombró nada más subir al trono calificó de usurarios gran número de los juros, en especial los que se dieron a hombres de negocios en recompensa de sus créditos, y prácticamente suspendió el pago de la deuda pública. ${ }^{61}$ Lo cierto es que en 1767 el colegio de Orduña decía poseer un único juro, situado en el 2,5\% de Sevilla, cuyo capital ascendía a 48.996 reales que devengaban una renta anual de 5.748. Poco más o menos la mitad de lo que percibía, por ejemplo, el colegio de Bilbao por sus catorce juros, alrededor de 11.600 reales al año. ${ }^{62}$ Mientras tanto Loyola, por ejemplo, tenía a esas alturas cinco juros por valor de 120.719 reales, situados sobre el servicio de millones y otros conceptos de la ciudad de Sevilla, la renta del Almojarifazgo de Indias y la renta de las salinas de Castilla la Vieja y su partido. ${ }^{63}$

Pero, sin duda alguna, la actividad dominante en el colegio de Orduña fue el crédito. Es bien sabido que la Compañía de Jesús, como otras instituciones religiosas, solía intervenir en el negocio bancario, aceptando depósitos privados y realizando préstamos a terceros. En ausencia de una banca oficial, la solvencia y la confianza que inspiraban las congregaciones religiosas respaldaban tales negocios, aunque a veces esa última acabase defraudada. El colegio de San Hermenegildo de Sevilla es un ejemplo de ello. ${ }^{64}$ Que los jesuitas de Orduña aceptaron depósitos de particulares queda corroborado en primer lugar por el montante localizado en el colegio en el momento de la expulsión, un total de 23.966 reales en metálico, de los cuales según el rector 1.800 pertenecían a un tal Miguel Gochi que los tenía precisamente en depósito. ${ }^{65}$

maravedís (32.000 ducados anuales). Lamentaban la estrechez con que vivían y no poder pagar las cargas y censos impuestos sobre ellos. Domínguez Ortiz, A. 1964: 329.

${ }^{61}$ Ibídem: 326.

${ }^{62}$ AHN. Clero-Jesuitas. Leg. 177. Exp. 6, ff. 2r-v.

${ }^{63} \mathrm{AHN}$. Clero-Jesuitas. Leg. 179. Exp. 1, 3, 4, 5 y 6.

${ }^{64}$ Aguado de los Reyes, J. 2003. «La actividad financiera de los jesuitas en Sevilla y su conexión con el tráfico indiano. El colegio de San Hermenegildo durante la procuraduría del padre Villar, 16321645». Revista de Historia Económica y Social 5: 9-34.

${ }^{65} \mathrm{AHN}$. Clero-Jesuitas. Leg. 184. Exp. 30, sin foliar. 


\section{Cuadro 3}

MONEDAS LOCALIZADAS EN EL COLEGIO DE ORDUÑA EN 1767

\begin{tabular}{|l|c|}
\hline \multicolumn{1}{|c|}{ TIPO DE MONEDA } & VALOR EN REALES \\
\hline 557 pesetas $^{66}$ y 589 reales de plata & 3.406 \\
\hline 19 doblones de a 8 & 5.700 \\
\hline 6 doblones de a 4 & 900 \\
\hline 28 doblones sencillos & 2.100 \\
\hline 165 escudos de oro & 3.300 \\
\hline 22 doblones de a 8 & 6.600 \\
\hline En varias monedas & 1.960 \\
\hline TOTAL & $\mathbf{2 3 . 9 6 6}$ \\
\hline
\end{tabular}

Con todo, donde mejor se manejó el colegio de Orduña fue en el préstamo a través de censos, ya a particulares, ya a instituciones. La rentabilidad de los censos había seguido una trayectoria paralela a la de los juros: muy alta en el siglo XVI (al 7\% anual) y equiparada a la baja a los juros en los años veinte del siglo XVII (al 5\%). No obstante, mientras éstos sufrieron a partir de entonces numerosos recortes, los censos escaparon a las garras del fisco. Será Felipe V quien acabe reduciendo juros y censos al 3\%, con la diferencia de que éstos mantuvieron ese aceptable tipo de interés mientras el de los juros se reducía casi a cero.

\section{Cuadro 4}

CENSOS DEL COLEGIO DE ORDUÑA EN EL SIGLO XVIII ${ }^{67}$

\begin{tabular}{|l|c|c|c|}
\hline & $\begin{array}{c}\text { PRINCIPAL } \\
\text { REALES }\end{array}$ & INTERÉS & $\begin{array}{c}\text { RENTA ANUAL } \\
\text { REALES }\end{array}$ \\
\hline $\begin{array}{l}\text { Censo contra doña } \mathrm{M}^{\mathrm{a}} \text { Antonia de Chava- } \\
\text { rría, vecina de Bilbao }\end{array}$ & 22.000 & $2,5 \%$ & 550 y $3 \mathrm{mrs}$ \\
\hline $\begin{array}{l}\text { Censo contra los estados del duque } \\
\text { de Béjar }\end{array}$ & 68.382 & $2,5 \%$ & 1.709 y $18 \mathrm{mrs}$ \\
\hline $\begin{array}{l}\text { Censo contra el convento de San Bernardo } \\
\text { de Salamanca que se cobraba por el oficio } \\
\text { de Valladolid }\end{array}$ & 44.000 & $2,5 \%$ & 1.100 \\
\hline
\end{tabular}

${ }^{66}$ Según señala Reglá, hacia 1725 España había recuperado la estabilidad monetaria que había perdido un siglo antes. Al real de a dos de plata provincial (devaluación de cerca del 1,50\% del real antiguo o nacional, a partir de 1717) comenzó a llamársele peseta, seguramente por influjo de su denominación catalana, aunque no todos los filólogos admiten esta etimología. Corominas cree, en efecto, que peseta es inseparable de peso y que sólo el sufijo eta es un catalanismo. Moll, en cambio, recuerda que ya a comienzos del siglo XV existían en Cataluña pecetes de plata. Ubieto, A. Reglá, J. Jover, J. M. y Seco, C. 1969. Introducción a la Historia de España: 463-464. Barcelona: Teide.

${ }^{67}$ AHN. Clero-Jesuitas. Leg. 184. Exp. 26, sin foliar (datos de 1767). 


\begin{tabular}{|l|c|c|c|}
\hline & $\begin{array}{c}\text { PRINCIPAL } \\
\text { REALES }\end{array}$ & INTERÉS & $\begin{array}{c}\text { RENTA ANUAL } \\
\text { REALES }\end{array}$ \\
\hline $\begin{array}{l}\text { Censo contra la Casa y estados del duque } \\
\text { de Medinaceli }\end{array}$ & 11.000 & $2,5 \%$ & 275 \\
\hline $\begin{array}{l}\text { Censo contra los estados del marqués } \\
\text { de Villafranca }\end{array}$ & 14.000 & $21 / 4$ & 315 \\
\hline $\begin{array}{l}\text { Censo contra los estados del duque } \\
\text { de Hijar }\end{array}$ & 85.154 & $21 / 4$ & 1.915 y $32 \mathrm{mrs}$ \\
\hline $\begin{array}{l}\text { Censo contra el Colegio de Jesuitas } \\
\text { de León }\end{array}$ & 13.000 & $2 \%$ & 260 \\
\hline $\begin{array}{l}\text { Tres censos contra la villa y vecinos } \\
\text { de Ameyugo (Burgos) }\end{array}$ & 66.000 & $2 \%$ & 1.320 \\
\hline $\begin{array}{l}\text { Dos censos contra el estado general } \\
\text { de Ameyugo (Burgos) }\end{array}$ & 4.180 & $2 \%$ & 83 y $20 \mathrm{mrs}$. \\
\hline $\begin{array}{l}\text { Cuatro censos contra la villa y propios } \\
\text { de Pinto cuyas escrituras paraban en el } \\
\text { oficio de Madrid }\end{array}$ & 230.803 & $3 \%$ & 6.924 y 3 mrs. \\
\hline $\begin{array}{l}\text { Censo contra el Colegio de Jesuitas } \\
\text { de Medina del Campo que su escritura } \\
\text { debe parar en el oficio de Madrid }\end{array}$ & 64.000 & $2 \%$ & 1.280 \\
\hline $\begin{array}{l}\text { Censo contra doña María Nicasia de Sal- } \\
\text { cedo Ortés de Velasco, vecina de Orduña }\end{array}$ & 12.716 & $2,5 \%$ & 317 y $30 \mathrm{mrs}$ \\
\hline TOTAL & $\mathbf{6 3 5 . 2 3 5}$ & $\mathbf{1 0 . 3 0 3}$ \\
\hline
\end{tabular}

En el colegio de Orduña se han podido contabilizar hasta dieciocho censos, por un importe de 635.235 reales de principal y unas rentas anuales de 10.303 a un interés del 2,5\% o inferior. Bastante más numerosos que los que poseían en el colegio de Bilbao, apenas ocho, si bien su principal alcanzaba los 738.047 reales. Hasta llegaban a compartir algún titular, como doña María Echevarría, una bilbaína que tenía contraídas deudas con ambos colegios.

Las instituciones eclesiásticas deudoras eran por lo general colegios de la misma Compañía, como los de León y Medina del Campo, tal vez en dificultades; Pero también de otras órdenes como el colegio cisterciense de San Bernardo de Salamanca, levantado en el siglo XVI extramuros de la ciudad, reformado en el XVII por Juan Setién Güemes, maestro del colegio de la Compañía de Jesús, y con ganas de expandirse en el XVIII a costa de la muralla salmantina para integrarse dentro del recinto urbano. ${ }^{68}$

${ }^{68}$ Los bernardos quisieron integrar el convento dentro del entorno urbano lo que les enfrentó con el Ayuntamiento sobre la propiedad de los terrenos sobre los que se quería asentar. En 1710 los monjes propusieron al municipio derribar el lienzo de la muralla situado frente a la fachada principal del colegio para conseguir un mayor desahogo visual y espacial. El Ayuntamiento denegó el permiso pero 


\section{DISTRIBUCIÓN DE LOS CENSOS POR COLECTIVOS}

\begin{tabular}{|l|c|c|}
\hline \multicolumn{1}{|c|}{ COLECTIVO } & PRINCIPAL / rs & \% en relación al TOTAL \\
\hline Instituciones eclesiásticas & 121.000 & 19 \\
\hline Municipios & 300.983 & 47,40 \\
\hline Particulares & 213.562 & 33,50 \\
\hline TOTAL & $\mathbf{6 3 5 . 2 3 5}$ & $\mathbf{9 9 , 9 0 \%}$ \\
\hline
\end{tabular}

Entre los municipios hablamos de localidades vinculadas claramente al comercio lanero. El municipio madrileño de Pinto, importante localidad en el conjunto de la llamada Cañada Galiana o Riojana, era titular de cuatro censos cuyas escrituras paraban en el oficio de Madrid, que en principio pagaban los intereses más altos del momento, el 3\%. No obstante, su desarrollo es confuso. Por un lado, se dice que sus réditos no se habían satisfecho desde el año 1722, a excepción de los de uno que se habrían ido abonando hasta 1767, aunque no se hace siquiera mención de él en el cuadro $\mathrm{N}^{\mathrm{o}} 6$ de los débitos de ese año. Sin embargo en nota aparte se señala que desde el año 1761 el interés de estos cuatro censos se había rebajado al 1,5\% por orden del Consejo de Castilla, con lo cual sólo debían rentar al año la mitad de lo que se ha hecho constar.

Mientras tanto, la localidad burgalesa de Ameyugo era titular de dos censos que sumaban 70.180 reales de principal, que al $2 \%$ redituaban algo más de 1.403. Ameyugo disfrutaba de una situación estratégica en el camino central que comunicaba la meseta con Bilbao y viceversa, el más transitado de los tres (el central por Orduña, el occidental por Valmaseda, y el oriental por Durango y Vitoria) que se conocían desde la Edad Media. Ese camino venía gozando además de un notable impulso respecto a los otros dos desde la primera parte del Setecientos, cuando los puertos de Bilbao y Santander disputaban como nunca por el control del tráfico lanero. Y Ameyugo, situada a la entrada de la hoz de Pancorbo, «presidía» la bifurcación de los caminos que desde ésta se dirigían hacia Logroño, hacia Vitoria y finalmente hacia Bilbao por Orduña, lo que la convertía en un paso mercantil obligado.

Por lo que hace al principal de los censos tomados por particulares, el $84 \%$ implicaba a miembros de la aristocracia castellana con el siguiente orden en función de su cuantía: El duque de Híjar encabezando la lista, seguido de cerca por el de Béjar ${ }^{69}$ y, ya de lejos, por el marqués de Villafranca del Bierzo -en prin-

en los años 80 se retomaron estos viejos planes, al parecer también sin éxito. Redondo Cantera, J. 1991. «Apuntes para la historia del desaparecido convento de San Bernardo de Salamanca: su edificio», en S.S. A.A. Tomo XVI: 453.

${ }^{69}$ Los duques de Béjar eran ya muy devotos de la Compañía en los primeros años del reinado de Felipe III, lo cual sorprendía a propios y extraños puesto que por aquel entonces el hermano mayor del 
cipio los condes de Benavente y más tarde los Álvarez de Toledo- y el duque de Medinaceli. ${ }^{70}$ Bien puede decirse que en esencia los jesuitas respetaron las consignas estipuladas en la concordia con los cabildos de no imponer ni tener censos en la ciudad, su jurisdicción y valle de Arrastaria (derecho que sin duda se reservaban las otras comunidades religiosas) salvo en un caso, el de doña Nicasia de Salcedo vecina de Orduña.

Claro que, encontrar a familias de la aristocracia castellana entre los deudores del colegio de Orduña -casi las mismas que en el de Bilbao- debe entenderse dentro de lo habitual. Domínguez Ortiz y otros autores han puesto de manifiesto repetidamente que la situación económica de estas principales casas nobles era desastrosa cuando menos desde finales del siglo XVI, a causa de la mala administración, el gasto ostentoso, y ya desde el reinado de Felipe IV, por los servicios hechos al Estado. Algunas de las familias que se cuentan entre los deudores de los colegios vizcaínos en el siglo XVIII mostraban ya serios problemas en aquel tiempo. ${ }^{71}$ Conforme avanzó el Seiscientos, y tras la guerra de Sucesión, sus apuros financieros fueron a más. Sin ir más lejos, en 1739 el duque de Medinaceli, por ejemplo, pidió a la Cámara de Castilla tres años de moratoria para abonar los réditos de sus censos, cuyo principal ascendía a casi treinta millones de reales de vellón. Llevaba sin pagarlos desde que las malas cosechas de 1734 le habían obligado a conceder moratorias a los labradores que llevaban en arriendo sus tierras. Y no sólo no había podido cobrarles las rentas, sino que los había tenido que alimentar, suministrarles grano para la siembra, y asistirlos en las enfermedades que habían sobrevenido, a lo que se unían los gastos y deudas ocasionados por sus servicios al rey.

Y eso que desde 1705, aún a pesar de las presiones de los eclesiásticos, sin duda entre los grandes censalistas, la política regia favoreció a los deudores, incluyendo a la aristocracia, al rebajar el interés de los censos del 5 al 3\% porque en la Castilla del siglo XVIII había un exceso de dinero que aspiraba a colocarse en renta fija.$^{72}$ El interés cobrado en Orduña y Bilbao era incluso más bajo, entre el 2 y el $2,5 \%$ y, al menos en la ciudad aduanera, se cobraban con bastante

duque era fraile dominico y porque pese a haber convento dominico en el lugar donde residían mandaban llamar a los jesuitas para confesar al duque, la duquesa y todos los de su casa. Lozano Navarro, J. 2005: 130 .

${ }^{70} \mathrm{El} 33,5 \%$ del total de censos (213.252 reales de principal) tenían como titulares a particulares, en su mayoría miembros de la aristocracia castellana (178.536 reales que suponen el 28,9\% del total) en el orden siguiente: El duque de Híjar con más de 85.000 reales, el duque de Béjar con más de 68.000, el marqués de Villafranca del Bierzo y el duque de Medinaceli con 14.000 y 11.000 reales respectivamente.

${ }^{71}$ En 1630 el pago de censos representaba para la Casa de Béjar el 25\% de sus rentas, para la de Priego el $35 \%$ y para la de Benavente el $45 \%$. Se trataba de porcentajes sobre ingresos brutos; sobre los líquidos montaban más de la mitad. Domínguez Ortiz, A. 2000. «Juros y censos en la Castilla del Seiscientos: una sociedad de rentistas», en A. M. Bernal (ed.): 801.

${ }^{72}$ Ibídem: 804 y 806. 
retraso. En el momento de la expulsión, se debían al colegio casi 15.475 reales por el impago de las rentas anuales de sus censos y juro, que acumulaban demoras de entre uno y cinco años.

\section{Cuadro 6}

DEBITOS DE LOS JUROS Y CENSOS A FECHA DE $1767^{73}$

\begin{tabular}{|c|c|c|}
\hline TITULAR & PERIODO DEBIDO & DEUDA \\
\hline Juro situado en el 2,5\% de Sevilla & Dos años & 11.496 rs. y $4 \mathrm{mrs}$ \\
\hline María Antonia de Chavarria & Dos años & $1.100 \mathrm{rs}$ \\
\hline Estados del duque de Béjar & Un año & 1.709 rs. y $18 \mathrm{mrs}$. \\
\hline Convento de San Bernardo de Salamanca & Cuatro años & $4.400 \mathrm{rs}$ \\
\hline Casa del duque de Medinaceli & Cinco años & 1.375 rs. \\
\hline Estados del marqués de Villafranca & Dos años & 630 rs. \\
\hline Estados del duque de Hijar & Dos años & 3.831 rs. y $30 \mathrm{mrs}$. \\
\hline Colegio jesuitas de León & Tres años & 780 rs. \\
\hline Villa y vecinos de Ameyugo & Un año & $1.320 \mathrm{rs}$. \\
\hline $\begin{array}{l}\text { María Nicasia de Salcedo Ortés } \\
\text { de Velasco }\end{array}$ & Un año & 317 rs. y $30 \mathrm{mrs}$ \\
\hline TOTAL & & 15.474 rs. y $10 \mathrm{mrs}$ \\
\hline
\end{tabular}

EL DESTINO DE LOS BIENES TRAS LA EXPULSIÓN

Hasta el momento de la expulsión, el colegio de Orduña había funcionado según los deseos del fundador, salvo que los miembros de la comunidad no eran catorce sino ocho, a saber: el rector Juan Miguel de Azcárate, el ministro Martín de Aresti y los operarios Luis de Arrevola, Francisco de Azcárate, Francisco Aguado, Nicolás López, Ignacio de Santa Coloma e Isidoro Jolí, este último afectado de demencia. Vivían acompañados de tres criados, encargados el uno de la sacristía y los otros dos del ganado y la cocina que cobraban por sus servicios un salario de 12 ducados anuales. Por lo demás, tal y como había dejado establecido Urdanegui, en el colegio había funcionado la escuela de primeras letras, la Cátedra de Gramática Latina y hasta la de Teología Moral y Casos de Conciencia, si bien esta última se hallaba en desuso en 1767, se habían venido impartiendo puntualmente los catorce sermones, y se habían venido respetando las demás condiciones acordadas con las otras comunidades religiosas en el momento de la fundación.

\footnotetext{
${ }^{73}$ AHN. Clero -Jesuitas. Leg. 184. Exp. 26, sin foliar.
} 
En la mañana del 3 de abril, el encargado de ejecutar la orden de extrañamiento que el rey había establecido por decreto de 27 de febrero fue don Andrés de Ciria, teniente general y alcalde mayor de las Encartaciones de Vizcaya, que fue comisionado para desalojar a los padres del colegio de Orduña. Al día siguiente, serían conducidos a Portugalete, puerto designado como «caja de embarque» para los jesuitas de Vizcaya, Álava y la Rioja. Para afrontar los gastos pertinentes, se hizo uso de los dineros localizados en el propio colegio. ${ }^{74}$ En días posteriores, y en número de 53, serían embarcados en dos navíos -el San Miguel y La Victoria- rumbo a La Coruña ${ }^{75}$ y más tarde a El Ferrol para dirigirse hacia su destino italiano. ${ }^{76}$ Quedaron en el colegio el rector Juan Miguel Azcárate para evacuar todas las diligencias que ordenaban las instrucciones, y el demente padre Isidoro Jolí, ambos «recogidos en depósito» en el convento de San Francisco de Orduña a la espera de concretar sus respectivos destinos.

Finalmente el padre Jolí sería conducido a la Casa de Inocentes de Valladolid por orden del conde de Aranda. El día 10 de mayo fue entregado a don Joseph del Barco, ministro de a pie de la Real Aduana de Orduña, para que en compañía de un criado lo condujesen a Vitoria a tomar una calesa que se tenía dispuesta al efecto. Por su parte, el rector sería conducido pasados unos días hasta Cartagena, después de cumplir con las diligencias estipuladas por las autoridades, esto es, dejar poder para la administración y cobranza de las rentas del colegio, y tras responder al interrogatorio del Fiscal, en el que por cierto no se consignó nada nuevo salvo que el colegio de Orduña contribuía con 326 reales para la manutención de los regulares expulsos de Portugal, que Azcárate pagó puntualmente dos años seguidos. Cumplidos tales requisitos, emprendió viaje por tierra a Cartagena en compañía del rector del colegio de Vitoria, padre Francisco Echalar, que habría de durar 29 días, ${ }^{77}$ para embarcar hacia el largo exilio italiano de la Compañía, al que por cierto ninguno de ellos, como tampoco el resto de los padres del colegio de Orduña, sobreviviría. ${ }^{78}$

\footnotetext{
${ }^{74} \mathrm{~A}$ los 23.966 reales en metálico hallados en el recinto se sumaron otros 1.948 reales y medio que se obtuvieron de la venta de diversos enseres, además del ganado, como el aceite, trigo, tocino, vino, manteca, pimienta, calvo y azafrán. Sumadas ambas partidas ascendían aun total de 25.914 reales y medio. De ellos se restarán 8.386 por los gastos destinados a la conducción de los regulares a Bilbao, satisfacción de soldadas, derechos de médicos, gastos de Audiencia, criados, ministros, caballerías y demás. Del destino de los 17.528 reales y medio nada sabemos. AHN. Clero-Jesuitas. Leg. 184. Exps. 26 y 30, sin foliar.

${ }^{75}$ AHN. Clero-Jesuitas, Leg. 177. Exp. 6, f. 1.

${ }^{76}$ Jiménez López, E. 1993. «El Ejército y la Marina en la expulsión de los jesuitas de España». Hispania Sacra, XLV, 92: 577-630.

${ }^{77}$ El viaje se inició el día 20 de junio de 1767 y se prolongó durante 29 días, tras superar diversos avatares, entre otros la enfermedad de Echalar que a punto estuvo de fallecer en el camino. Los gastos del viaje se elevaron a 3.506 reales, superando en 5 reales y 22 maravedís lo presupuestado y finalmente abonado por las autoridades (3.500 reales y 12 maravedís). AHN. Clero-Jesuitas. Leg. 184. Exp. 32, sin foliar, [Cuenta presentada en Orduña por Pedro de San Pedro el 3 de septiembre de 1767].

${ }^{78}$ Así consta por el Diario del padre Luengo. Fernández Arrillaga, I. 2004. El destierro de los jesuitas castellanos, 1767-1815: 126-132. Salamanca: Junta de Castilla y León. Consejería de Cultura y Turismo.
} 
Una vez expulsos los jesuitas, dos instituciones se hicieron con las instalaciones de la iglesia y el colegio. A la iglesia se trasladó en 1769 la parroquia de San Juan del Mercado, que era de mala fábrica y se demolió, pasando a llamarse San Juan el Real (en la actualidad la Sagrada Familia). El colegio y las habitaciones se convirtieron en Casa de Misericordia en 1783, con dotación, reglas de gobierno, escuela, maestros y todo el orden a perpetuidad y beneficio público. En cuanto a los censos, los correspondientes a la propia Orden se extinguieron «muertos por ser contra colegio». Mientras tanto, el censo de de doña María Antonia de Echavarría, la viuda bilbaína, fue redimido en 1772, habiéndose pagado hasta entonces sus réditos con mayor o menor demora. También los de los otros censos se fueron cobrando, al menos los más próximos. Según los datos de 1771, tanto el Síndico Procurador de Ameyugo, como el conde de Francos en nombre de su madre doña Nicasia de Salcedo, abonaron puntualmente los suyos. ${ }^{79}$ De los demás censos y juros, nada sabemos.

Sobre las fincas poseemos algún dato más. Por lo que respecta a la huerta del colegio y a las casas, corrieron distinta suerte. La huerta pegante al colegio fue puesta en arrendamiento, si bien en 1772 todavía no había aparecido nadie que quisiese arrendarla. Algo parecido sucedió con la casa principal y la casa horno de Endayacoa sitas en San Sebastián, aunque pronto se sacaron a la venta. La casa situada en la calle mayor y el horno situado en su trasera en la calle Ballena, había sido comprada a doña Mariana Mañeras vecina de Madrid hacia 1762 por 96.000 reales, pero al sacarla a la venta la tasación fue de 172.292,5, es decir, casi el doble de su valor. Esta circunstancia hizo que durante mucho tiempo no apareciese comprador, hasta que en febrero de 1771 un vecino de San Sebastián (según algunas fuentes notario en Orduña) Juan Bautista Jimenez Bretón presentó postura, eso sí, extrañado por tan alta tasación. Tanto, que en su opinión «no pudo menos de haverse padezido error» porque ni las reparaciones que habían hecho los jesuitas, ni el corto tiempo transcurrido desde su compra había podido darle «semexante estimazion ni crezimiento». Ofreció 112.500 reales de vellón, que se comprometió a pagar antes de seis meses de concedido el remate. ${ }^{80}$

Reunida la Junta Municipal de Orduña, formada por el escribano Manuel Antonio Ortiz de Zárate nombrado Comisionado de las temporalidades, Andrés Francisco de Oribe y Salazar vicario de Orduña y diputado por el obispo, Enri-

\footnotetext{
${ }^{79}$ El Síndico Procurador de la villa de Ameyugo remitió los 1.320 reales por los réditos de tres censos de 66.000 reales de capital, más otros 83 reales y 20 maravedís de los otros dos censos de 4.180 reales de principal; El conde de Francos, como hijo y heredero de doña Nicasia Salcedo, viuda de Orduña, abonó los 317 reales de los réditos que pesaban en el censo de su madre; Igualmente doña María de Echavarría abonó los 550 reales de réditos correspondientes al suyo aunque, como se ha señalado, sería redimido al año siguiente.

${ }^{80}$ AHN. Clero-Jesuitas. Leg. 184. Exp. 18, f. 1. [La postura se presenta en Orduña el día 8 de febrero de 1771].
}

Hispania Sacra, LXIV

129, enero-junio 2012, 309-343, ISSN: 0018-215-X, doi: 10.3989/hs.2012.011 
que de Jausoro y el conde de Francos, diputado y personero que eran, aceptaron la oferta forzados por la falta de más postores, a pesar de que los 112.500 reales no llegaban a cubrir las tres cuartas partes del importe de su tasación. Por orden del Consejo, la postura de Jiménez Bretón se sacó en público pregón con la esperanza de que apareciesen más postores. Entre el 20 de mayo y el 10 de noviembre fueron incontables los pregones, pero no hubo resultados. Finalmente, ese día las casas fueron rematadas en Jiménez Bretón, en un acto que tuvo lugar en el pórtico de San Juan el Real, la vieja iglesia que había sido de los jesuitas. El postor, tal vez por afianzar su logro, se comprometió a pagar el remate al contado y no en seis meses.

El 10 de diciembre el nuevo propietario recibió la correspondiente escritura después de entregar los 112.500 reales pertinentes. Pero Jiménez Bretón actuaba en nombre de otros, pues en ese mismo momento y ante el mismo escribano «cedió el remate y escritura de venta» a dos comerciantes residentes en San Sebastián, probablemente extranjeros, don Alejandro Rieumes y don Jerónimo Burgue. Sin embargo, cuando ya habían abonado lo estipulado, e incluso después de realizar varias obras en las casas, un nuevo postor entró en liza, don Juan Francisco de Cardavéraz, ${ }^{81}$ también vecino de San Sebastián, amparándose en que aquella concesión no era legal al no haberse seguido los trámites precisos en la Junta Provincial de San Sebastián. Su postura mejoraba en 4.500 reales la anterior, situándola en 117.000. Agraviados, Rieumes y Burgue exigieron que se les devolvieran los caudales del remate pero también los 3.848 reales que, según ellos habían empleado en limpiarla y recomponerla. Con todo, en el interim aún aparecería un nuevo postor, don Bernardo Cristóbal Jiménez Bretón, beneficiado de las Parroquias Unidas de Orduña, al que cabe suponer hermano del primer postor. Ofrecía por esta vez 1.500 reales más (120.500). ${ }^{82}$

Sin embargo, sin que sepamos de acuerdo a que intereses, finalmente la postura del beneficiado se desestimó por su condición de presbítero, lo cual le incapacitaba como postor a tenor de lo dispuesto por la Real Cédula de 27 de marzo de 1769 en la que se ordenaba que las posturas admisibles habían de darse en personas seglares y contribuyentes. Esa doble condición la cumplía quien finalmente se llevó el gato al agua, don Antonio Tasttet, vecino de San Sebastián, que se quedó con las casas por 117.000 reales de vellón líquidos, en el remate efectuado el 28 de junio de 1772. Se da la circunstancia de que este sujeto presentó como fiador a Juan Bautista Jimenez Bretón, el primer postor. En esta ocasión la operación contó con el apoyo de la Junta Provincial, y en particular de su

${ }^{81}$ Seguramente pariente de Agustín de Cardavéraz, famoso predicador y escritor en euskera, de origen guipuzcoano, que en 1733 se hallaba en el colegio de jesuitas de Bilbao. Cifuentes Pazos, J. M. 2003. «El clero de Bilbao en el Antiguo Régimen. Número, procedencia geográfica y extracción social». Bidebarrieta, XII: 286.

${ }^{82}$ AHN. Clero-Jesuitas. Leg. 184. Exp. 18, f. 41, [Madrid, a 25 de mayo de 1772] y ff. 67-70, [Orduña, 28 de junio de 1772]. 
presidente el marqués de Basscourt. Además del remate, el nuevo propietario tuvo que desembolsar los 2.972 reales en los que se tasaron las mejoras que habían realizado Rieumes y Borgue. Así pues, en total Tasttet abonó 119.972 reales, que se depositaron en don Francisco de San Cristóbal, Administrador de la Aduana de Orduña, y que le permitieron disfrutar de sus nuevas posesiones a partir de septiembre de 1772 .

Las otras casas pertenecientes al colegio se mantuvieron en arrendamiento como hasta entonces. La de la calle Burgos de Orduña, que en origen perteneció al fundador, se mantuvo en la misma persona, Blas del Campo, a cambio de 118 reales anuales y 7,5 fanegas de trigo cuyo valor, según las oscilaciones del precio en el mercado alcanzaban los 260 reales anuales. ${ }^{83}$ La casería de Aloria permaneció arrendada en Diego de Barrio, vecino de la citada localidad, por una renta de 18 fanegas de trigo valoradas en 712 reales de vellón. Pasados unos años se desprendieron de otros bienes menores, como el ajuar, que siguiendo la tasación llevada a cabo por la costurera Manuela de Cubillas se vendió por 605 reales. ${ }^{84}$

En definitiva, después de superar los muchos contratiempos que precedieron a su fundación, hasta 1767 el colegio de Orduña funcionó en lo fundamental según los meticulosos planes de su fundador el marqués de Villafuerte. A la escuela de primeras letras se sumaron la Cátedra de Gramática Latina y la de Teología Moral y Casos de Conciencia. Sobre la base del legado de Urdanegui, en lo cualitativo el patrimonio amasado con el paso de los años por los jesuitas en Orduña fue similar al acumulado en otros núcleos mercantiles de la zona como Bilbao o Vitoria, esto es, muy apoyado en el crédito y la deuda pública y muy poco en los bienes inmuebles. No obstante, a diferencia de los colegios de aquellas, en Orduña dieron cabida a la explotación agrícola y ganadera. Tras la expulsión, la Junta Municipal de Temporalidades no tuvo excesivos problemas a la hora de desprenderse de los bienes de los ignacianos de Orduña. Todo lo contrario de lo que vino a ocurrir por ejemplo en Bilbao, donde necesitaron 24 años salpicados de sucesivas subastas. Eso sí, en la ciudad aduanera conservaron sus propiedades en condiciones de arrendamiento similares a las estipuladas antes del extrañamiento, mientras que las propiedades localizadas en San Sebastián fueron sacadas a subasta yendo a parar a manos de comerciantes donostiarras. Avanzado ya el siglo XIX, el Ayuntamiento de Orduña pidió el retorno de los jesuitas, que el 1 de octubre de 1870 retomaron su actividad académica en lo que pasó a llamarse Colegio Municipal de La Antigua.

\footnotetext{
${ }^{83}$ Ibídem. Exp. 17; En realidad sólo se computan 6,5 fanegas ya que por acuerdo entre partes se le rebaja una fanega por razón del pan cocido que se lleva a la capilla citada. En 1771 el precio computado asciende a 40 reales por fanega que es el precio que entonces alcanza en los mercados.

${ }^{84}$ AHN. Clero-Jesuitas. Leg. 184. Exp. 29, sin foliar, [Tasación efectuada el 20 de septiembre de 1771 por orden de Manuel Antonio Ortiz de Zárate Garibay, comisionado de las Temporalidades].

Hispania Sacra, LXIV

129, enero-junio 2012, 309-343, ISSN: 0018-215-X, doi: 10.3989/hs.2012.011
} 


\section{BiBLIOGRAFÍA}

Aguado de los Reyes, J. 2003. «La actividad financiera de los jesuitas en Sevilla y su conexión con el tráfico indiano. El colegio de San Hermenegildo durante la procuraduría del padre Villar, 1632-1645». Revista de Historia Económica y Social 5: 9-34.

Álvarez Barrientos, J. 1989. José Antonio de Armona y Murga, corregidor de Madrid en tiempos de Carlos III: Madrid: Artes Gráficas Municipales.

Angulo Morales, A. 1995. Las puertas de la vida y la muerte: la administración aduanera en las provincias vascas (1690-1780). Bilbao: Servicio Editorial de la Universidad del País Vasco/EHU.

Angulo Morales, A. 1999. «La Real Congregación de San Ignacio de Loyola de los naturales y originarios de las tres Provincias Vascas en la Corte de Madrid (17131896)», en A. Garritz (coord.), Los vascos en las regiones de México: 15-34. México: Universidad Nacional Autónoma de México.

Benito Aguado, T. 2001. «La resistencia al asentamiento de los jesuitas en el País Vasco: Vitoria (1583-1751)» en R. Porres Marijuán (ed.), Poder, resistencia y conflicto en las Provincias Vascas, siglos XV-XVIII: 339-366. Bilbao: Servicio Editorial de la Universidad del País Vasco/EHU.

Benito Aguado, T. 2001. La sociedad vitoriana en el siglo XVIII: el clero, espectador y protagonista. Bilbao: Servicio Editorial de la Universidad del País Vasco/EHU.

Bilbao, L. M. 1983. «Exportación y comercialización de lanas de Castilla durante el siglo XVII» en El pasado histórico de Castilla y León. Vol. II. Edad Moderna. Burgos: Junta de Castilla y León. Consejería de Educación y Cultura.

Bilbao, L. M. 1994. «La economía de la Provincia de Álava en la etapa foral, 14581876» en Actas de las Juntas Generales de Álava. Vol. 5. Vitoria: Juntas Generales de Álava.

Bilbao, L. M. 2003. «Comercio y transporte internacionales en los puertos de Vizcaya y Guipúzcoa durante el siglo XVII (1600-1650. Una visión panorámica». Itsas Memoria. Revista de Estudios marítimos del País Vasco 4.

Burrieza Sánchez, J. 2003. «La recompensa de la eternidad. Los fundadores de los colegios de la Compañía de Jesús en el ámbito vallisoletano». Revista de Historia Moderna 21: 29-56.

Burrieza Sánchez, J. 2004. «El poder de las palabras de la Compañía de Jesús en el Valladolid Moderno» en A. Alvar, J. Contreras y J. I. Ruiz (eds.), Política y Cultura en la época Moderna. Cambios dinásticos. Milenarismos, Mesianismos y Utopías. Madrid: Universidad de Alcalá.

Burrieza Sánchez, J. 2009. «Los jesuitas: de las postrimerías a la muerte ejemplar». Hispania Sacra 61, 124: 513-544.

Catalán Martínez, E. 2000. El precio del purgatorio. Los ingresos del clero vasco en la Edad Moderna. Bilbao: Servicio Editorial de la Universidad del País Vasco/EHU.

Cifuentes Pazos, J. M. 2003. «El clero de Bilbao en el Antiguo Régimen. Número, procedencia geográfica y extracción social». Bidebarrieta, XII.

Domínguez Ortiz, A. 1964. Política y hacienda de Felipe IV. Madrid: Ediciones Pegaso.

Domínguez Ortiz, A. 2000. «Juros y censos en la Castilla del Seiscientos: una sociedad de rentistas», en A. M. Bernal (ed.), Dinero, moneda y crédito en la Monarquía Hispánica. Madrid: Marcial Pons. 
Egido, T. (coord.). 2004. Los jesuitas en España y en el mundo hispánico. Madrid: Marcial Pons. Ediciones de Historia.

Fernández Arrillaga, I. 2004. El destierro de los jesuitas castellanos, 1767-1815. Salamanca: Junta de Castilla y León. Consejería de Cultura y Turismo.

Fernández de Pinedo, E. 1974. Crecimiento económico y transformaciones sociales del País Vasco, 1100/1850. Madrid: Siglo XXI Editores.

Fernández de Pinedo, E. 1998. «Los altibajos mercantiles del Consulado de Bilbao en los años 80 y 90» en L. A. Ribot y E. Belenguer (coords.) Las sociedades ibéricas y el mar a finales del siglo XVI. Tomo IV. La Corona de Castilla. Madrid: Sociedad Estatal Lisboa'98.

Fernández de Pinedo, E. 2000. «La deuda pública y los juristas laicos, 1550-1650», en A. M. Bernal, A. M. (ed.), Dinero, moneda y crédito en la Monarquía Hispánica. Madrid: Marcial Pons.

Galán García, A. 1995. El Oficio de Indias de los jesuitas en Sevilla, 1566-1767. Sevilla: Fundación Fondo de Cultura.

García Guerra, E. M. 2006. «Itinerarios mundiales de una moneda supranacional: el real de a ocho o peso durante la Edad Moderna». Studia Histórica. Edad Moderna 28.

Jiménez López, E. 1993. «El Ejército y la Marina en la expulsión de los jesuitas de España». Hispania Sacra, XLV, 92: 577-630.

León Sáenz, J. 2009. «Los astilleros y la industria marítima en el Pacífico americano. Siglos XVI-XIX». Diálogos. Revista electrónica. Universidad de Costa Rica 10: 1.

López Martínez, A. 1992. «Los juros eclesiásticos. Participación de los conventos andaluces en la deuda pública castellana». Revista de Historia Económica, 3.

López Martínez, A. 1992. La economía de las órdenes religiosas en el Antiguo Régimen. Sus propiedades y rentas en el reino de Sevilla. Sevilla: Diputación Provincial.

López Martinez, A. 2000. «Los jesuitas y su intermediación financiera en la Carrera de Indias» en A. M. Bernal (ed.), Dinero, moneda y crédito en la Monarquía Hispánica. Madrid: Marcial Pons.

Lozano Navarro, J. 2005. La Compañía de Jesús y el poder en la España de los Austrias. Madrid: Cátedra.

Malaxechevarría, J. 1926. La Compañía de Jesús por la instrucción del País Vasco en los siglos XVII y XVIII. San Sebastián.

Martinez Naranjo, F. J. 2002. «Aproximación al estudio de las Congregaciones de Estudiantes en los Colegios de la Compañía de Jesús durante la Edad Moderna». Revista de Historia Moderna de la Universidad de Alicante, 20.

Otazu, A. y Díaz de Durana, J. R. 2008. El espíritu emprendedor de los vascos. Madrid: Silex.

Porres Marijuán, R. 1989. Gobierno y administración de la ciudad de Vitoria en la primera mitad del siglo XVIII. Vitoria: Diputación Foral de Álava.

Porres Marijuán R. y Benito Aguado, T. 2000. «El estatuto de limpieza de sangre y sus repercusiones en Vitoria en tiempos de Felipe II». Hispania, LX/2, 205: 515-562.

Porres Marijuán, R. 2005 «La Compañía de Jesús en las ciudades vascas: intrigas políticas y agitación social en la fundación de los colegios de Vitoria y Bilbao (15771604)» en E. García Fernández (ed.), Bilbao, Vitoria y San Sebastián, espacios para mercaderes, clérigos y gobernantes: 185-250. Bilbao: Servicio Editorial de la Universidad del País Vasco/EHU. 
Porres Marijuán, R. 2009. «Las redes mercantiles atlánticas y la instalación de los jesuitas en Bilbao, 1551-1604» en I. Dubert y H. Sobrado (eds.), El mar en los siglos moderno: 499-511. Santiago de Compostela: Universidad Santiago de Compostela.

Porres Marijuán, R. 2012. «Maniobras politicas y convulsion social en la aproximación de los jesuitas al País Vasco en el siglo XVI», en Los jesuitas: religión, política y educación, siglos XVI-XVIII: Madrid: Polifemo (en prensa).

Priotti, J. P. 1999. «Una conquista al revés o la penetración de los mercaderes noreuropeos y americanos en la Península Ibérica», en O. Mazín Gómez (Eed.) México en el mundo hispánico. Vol. I. Zamora: El Colegio de Michoacan. Colección Memorias.

Priotti, J. P. 2003. «Protagonistas de la ciudad y comerciantes europeos en el mercado bilbaíno del siglo XVI». Bidebarrieta, XII.

Priotti, J. P. 2005. Bilbao y sus mercaderes en el siglo XVI. Génesis de un crecimiento. Bilbao: Diputación Foral de Vizcaya.

Redondo Cantera, J. 1991. «Apuntes para la historia del desaparecido convento de San Bernardo de Salamanca: su edificio», en S.S. A.A. Tomo XVI.

Rivera Vázquez, E. 1991. «Crónica General de la Provincia de Castilla», en San Ignacio de Loyola y la Provincia jesuítica de Castilla. León: Provincia de Castilla S. J.

Salazar Arechalde, J. I. (ed.) 2002. Apuntaciones históricas y geográficas de la antigüedad, nombre y privilegios de la ciudad de Orduña en el M.N. y M.L. Señorio de Vizcaya. Bilbao: Diputación Foral de Vizcaya. Instituto de Estudios Territoriales de Bizkaia.

Tellechea Idígoras, J. I. 1997. Una historia turbulenta. La fundación de la Compañía de Jesús en San Sebastián (1619-1627): San Sebastián: Fundación Social Cultural Kutxa.

Ubieto, A. Reglá, J. Jover, J. M. y Seco, C. 1969. Introducción a la Historia de España. Barcelona: Teide. 